\title{
Transcriptional regulation by calcium, calcineurin, and NFAT
}

\author{
Patrick G. Hogan, ${ }^{1}$ Lin Chen, ${ }^{3}$ Julie Nardone, ${ }^{1}$ and Anjana Rao ${ }^{1,2,4}$ \\ ${ }^{1}$ The Center for Blood Research and ${ }^{2}$ Department of Pathology, Harvard Medical School, Boston, Massachusetts 02115, USA; \\ ${ }^{3}$ Department of Chemistry and Biochemistry, University of Colorado at Boulder, Boulder, Colorado 80309-0215, USA
}

The NFAT family of transcription factors encompasses five proteins evolutionarily related to the Rel/NFkB family (Chytil and Verdine 1996; Graef et al. 2001b). The primordial family member is NFAT5, the only NFATrelated protein represented in the Drosophila genome. NFAT5 is identical to TonEBP (tonicity element binding protein), a transcription factor crucial for cellular responses to hypertonic stress (López-Rodríguez et al. 1999; Miyakawa et al. 1999). We focus here on the remaining four NFAT proteins (NFAT1-NFAT4, also known as NFATc1-c4; see Table 1), referring to them collectively as NFAT.

The distinguishing feature of NFAT is its regulation by $\mathrm{Ca}^{2+}$ and the $\mathrm{Ca}^{2+} /$ calmodulin-dependent serine phosphatase calcineurin. NFAT proteins are phosphorylated and reside in the cytoplasm in resting cells; upon stimulation, they are dephosphorylated by calcineurin, translocate to the nucleus, and become transcriptionally active, thus providing a direct link between intracellular $\mathrm{Ca}^{2+}$ signaling and gene expression. NFAT activity is further modulated by additional inputs from diverse signaling pathways, which affect NFAT kinases and nuclear partner proteins. In the first part of this review, we describe the influence of these multiple inputs on the nuclear-cytoplasmic distribution and transcriptional function of NFAT.

Recent structural data emphasize the remarkable versatility of NFAT binding to DNA. At composite NFAT:AP-1 elements found in the regulatory regions of many target genes, NFAT proteins bind cooperatively with an unrelated transcription factor, AP-1 (Fos-Jun; Chen et al. 1998). At DNA elements that resemble NFKB sites, NFAT proteins bind DNA as dimers (Giffin et al. 2003; Jin et al. 2003). In the second section of this review, we describe these two modes of DNA binding by NFAT. NFAT also acts synergistically with transcription factors other than Fos and Jun, but the structural basis for synergy remains unknown. Drawing on published structures, we discuss the potential cooperation of NFAT with other classes of DNA-binding proteins.

${ }^{4}$ Corresponding author.

E-MAIL arao@cbr.med.harvard.edu; FAX (617) 278-3280.

Article and publication are at http://www.genesdev.org/cgi/doi/10.1101/ gad.1102703.
It is clear that NFAT activates transcription of a large number of genes during an effective immune response (Rao et al. 1997; Kiani et al. 2000; Serfling et al. 2000; Macián et al. 2001). In the third part of this review, we present information obtained from these studies, highlighting experimental and bioinformatics approaches to identifying NFAT target genes. We discuss the finding that NFAT and NFAT-Fos-Jun complexes activate distinct subsets of target genes in lymphocytes (Macián et al. 2002). We also describe a novel aspect of gene regulation by NFAT, in which this transcription factor participates in an early phase of chromatin remodeling that occurs at specific genetic loci in differentiating $\mathrm{T}$ cells (Avni et al. 2002).

There is evidence that NFAT regulates cell differentiation programs in cell types other than immune cells (Crabtree and Olson 2002; Horsley and Pavlath 2002; Graef et al. 2003; Hill-Eubanks et al. 2003). In the last section of this review, we select three differentiation programs-fiber-type specification in differentiated skeletal muscle, cardiac valve development, and osteoclast differentiation-for detailed consideration. We evaluate the evidence for NFAT involvement, point out novel cellular and molecular mechanisms that might regulate this familiar transcription factor, and discuss how NFAT exerts its biological effects. Because the phenotypes of NFAT knockout mice have been reviewed elsewhere (Crabtree and Olson 2002; Horsley and Pavlath 2002), we refer to them only as necessary to illustrate specific points.

\section{Cellular inputs affecting NFAT}

$\mathrm{Ca}^{2+}$ and calcineurin

NFAT is activated by cell-surface receptors coupled to "store-operated" $\mathrm{Ca}^{2+}$ entry via phospholipase C (Fig. 1). The importance of this process is illustrated by patients with a rare form of hereditary severe combined immunodeficiency (Feske et al. 2000, 2001). T cells from these patients showed multiple cytokine deficiency and a selective inability to activate NFAT; NFkB and AP-1 activation were normal. The primary defect was traced to a pronounced reduction in store-operated $\mathrm{Ca}^{2+}$ entry, which led to a marked impairment in activation of all NFATs. 
Hogan et al.

Table 1. List of NFAT proteins

\begin{tabular}{llll}
\hline Protein & Other names & \multicolumn{1}{c}{ Regulation } & \multicolumn{1}{c}{ References } \\
\hline NFAT1 & NFAT $\rho$, NFATc2 & $\mathrm{Ca}^{2+} /$ calcineurin & McCaffrey et al. 1993 \\
NFAT2 & NFATc, NFATc1 & $\mathrm{Ca}^{2+} /$ calcineurin & Northrop et al. 1994 \\
NFAT3 & NFATc4 & $\mathrm{Ca}^{2+} /$ calcineurin & Hoey et al. 1995 \\
NFAT4 & NFATx, NFATc3 & $\mathrm{Ca}^{2+} /$ calcineurin & Hoey et al. 1995; Masuda et al. 1995; \\
& & Ho et al. 1995 \\
NFAT5 & TonEBP & Osmotic stress & Miyakawa et al. 1999; \\
& & Integrin $(\alpha 6 \beta 4)$ activation & López-Rodríguez et al. 1999; Jauliac et al. 2002 \\
\hline
\end{tabular}

NFAT activation is initiated by dephosphorylation of the NFAT regulatory domain, a conserved $~ 300$-aminoacid region located $\mathrm{N}$-terminal to the DNA-binding domain (Fig. 2). This domain is encoded in a single exon in all four NFAT proteins from all vertebrate species for which sequence data are available (Graef et al. 2001b). The domain is heavily phosphorylated in resting cells, with the phosphorylated residues (serines) distributed among four classes of conserved serine-rich sequence motifs (SRR-1, SPxx repeat, SRR-2, and KTS motifs; Fig. 2; Beals et al. 1997a; Okamura et al. 2000). Calcineurin dephosphorylates three of the four types of motifs, thus triggering NFAT nuclear accumulation and increasing the affinity of NFAT for its target sites in DNA /Shaw et al. 1995; Okamura et al. 2000; Porter et al. 2000; Neal and Clipstone 2001). It is not formally known whether dephosphorylation is an ordered process, but mass spectrometry experiments suggest that the SRR1 region, which is immediately adjacent to the major calcineurin docking site (PxIxIT; see below), is preferentially dephosphorylated at low calcineurin activity (Okamura et al. 2000). NFAT mutants with small deletions or $\mathrm{S} \rightarrow \mathrm{A}$ substitutions in the SRR1 region are more susceptible than wild-type NFAT to dephosphorylation of the SPxx repeats by calcineurin (Zhu et al. 1998; Aramburu et al. 1999).

Efficient dephosphorylation requires a docking interaction between NFAT and calcineurin (Aramburu et al. 1998, 1999; Chow et al. 1999; J. Liu et al. 2001). The major docking site for calcineurin is located at the $\mathrm{N}$ terminus of the NFAT regulatory domain, and has the consensus sequence PxIxIT (SPRIEIT in NFAT1; Fig. 2). The individual NFAT proteins possess characteristic PxIxIT sequences with a low affinity for calcineurin $\left(\mathrm{K}_{\mathrm{d}}=10-30 \mu \mathrm{M}\right)$, needed to maintain sensitivity to environmental signals and prevent constitutive activation of NFAT. Substitution of the SPRIEIT sequence of NFAT1 with HPVIVIT, a higher-affinity version obtained by peptide selection, increased the basal calcineurin sensitivity of the protein and resulted in partial nuclear localization (Aramburu et al. 1999). The A238L protein of African swine fever virus, a potent viral inhibitor of NFAT, contains a PKIIIT sequence that is likely to be intermediate in affinity between the SPRIEIT and HPVIVIT sequences (Miskin et al. 2000). The surface of NFAT-calcineurin interaction is likely to be more extensive than the PxIxIT motif, however, because a second interacting sequence has been identified in NFAT2 and in NFAT4
(Liu et al. 1999; Park et al. 2000). This sequence (calcineurin-binding sequence B in Fig. 2) is moderately conserved in the NFAT proteins and resembles a highly conserved sequence in the calcineurin inhibitors DSCR1/ MCIP1 (Fuentes et al. 2000; Kingsbury and Cunningham 2000; Rothermel et al. 2000). Structural and cell-biological studies should establish whether NFAT and DSCR1/ MCIP1 use this region for calcineurin binding and inhibition, and whether they compete for calcineurin binding in cells.

In overexpression experiments, NFAT nuclear localization is accompanied by some relocalization of calcineurin from the cytoplasm into the nucleus (Shibasaki et al. 1996). This process has been documented for endogenous calcineurin and NFAT1 in primary keratinocytes (Al-Daraji et al. 2002), but is not readily observed for the endogenous proteins in other cell types. Nevertheless, it is clear that calcineurin is present in the nucleus of stimulated cells, where it maintains the dephosphorylated status and nuclear localization of NFAT. When $\mathrm{Ca}^{2+}$ entry is prevented or calcineurin activity is inhibited, NFAT is rephosphorylated by NFAT kinases and rapidly leaves the nucleus $\left(\mathrm{t}_{1 / 2} \sim 15 \mathrm{~min}\right)$, and NFATdependent gene expression is terminated (Garrity et al. 1994; Loh et al. 1996a,b; Timmerman et al. 1996). As a result of this absolute dependence on $\mathrm{Ca}^{2+} /$ calcineurin signaling, NFAT has a remarkable ability to sense dynamic changes in intracellular $\mathrm{Ca}^{2+}$ levels $\left(\left[\mathrm{Ca}^{2+}\right]_{\mathrm{I}}\right)$ and frequencies of $\mathrm{Ca}^{2+}$ oscillations in cells (Dolmetsch et al. 1997, 1998; Li et al. 1998).

The parameters of $\mathrm{Ca}^{2+} /$ calcineurin signaling can be modulated in diverse ways. The TNF family member RANKL elicits $\mathrm{Ca}^{2+}$ oscillations in differentiating osteoclasts (Takayanagi et al. 2002). In T cells, TGF $\beta$ inhibits Tec kinase activity and thereby $\mathrm{Ca}^{2+}$ influx (Chen et al. 2003). Calcineurin activity may be controlled independently of $\left[\mathrm{Ca}^{2+}\right]_{\mathrm{I}}$ by modulating the expression of members of the DSCR/MCIP family of endogenous calcineurin inhibitors. This process incorporates a negative feedback loop: Calcineurin/NFAT signals up-regulate DSCR1/MCIP1 expression, which then feeds back to down-regulate calcineurin activity (J. Yang et al. 2000).

\section{NFAT kinases}

The 13 serine residues that control NFAT1 nuclear localization are located in diverse sequence contexts that are unlikely to be recognized by a single kinase (Fig. 2). 


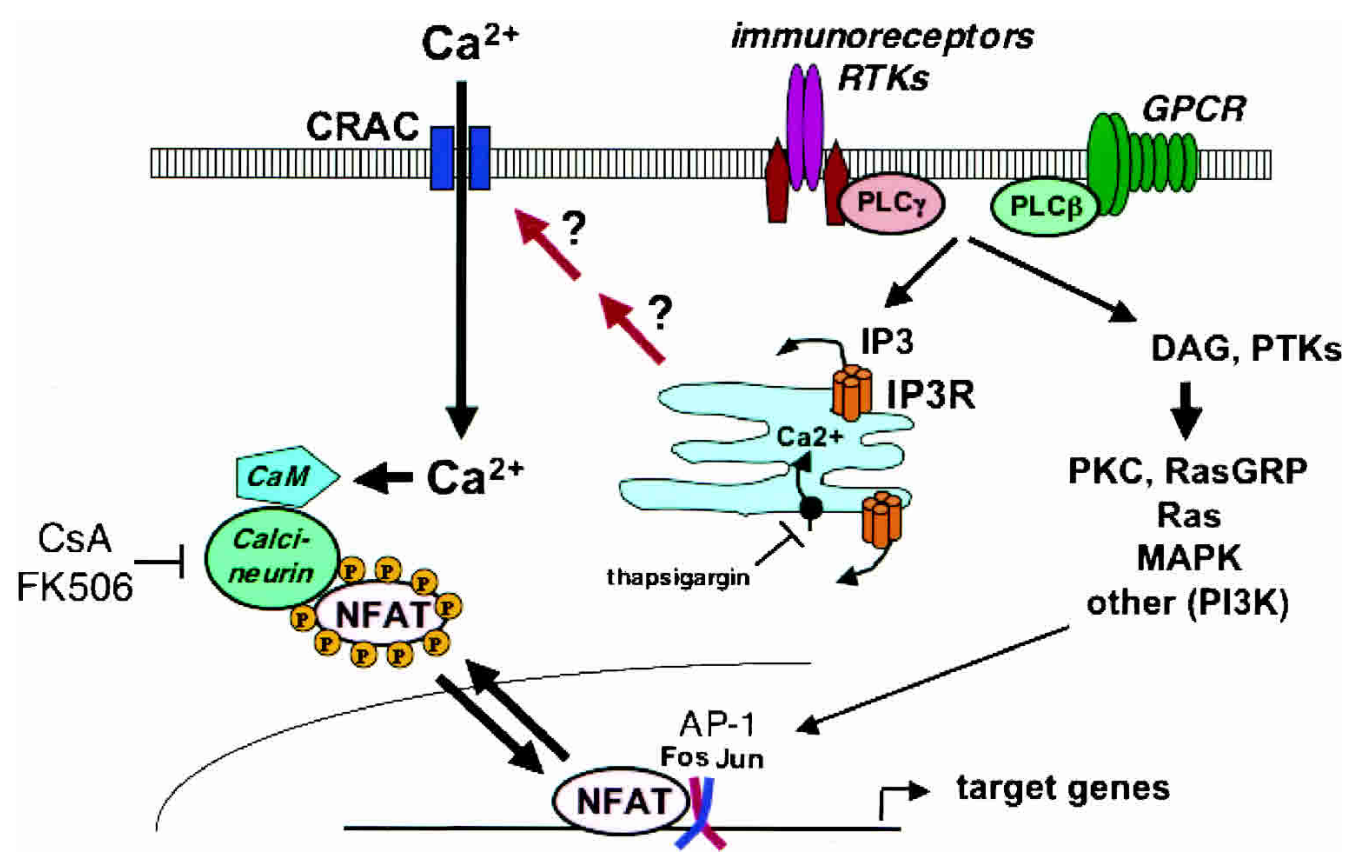

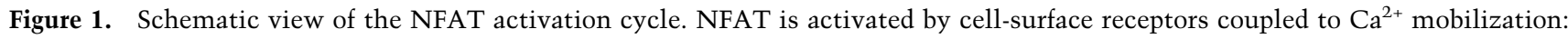
Immunoreceptors and receptor tyrosine kinases (RTKs) activate phosphatidylinositol-specific phospholipase C (PLC)- $\gamma$, while Gprotein-coupled receptors (GPCR) activate PLC $\beta$. PLC activation raises intracellular free $\mathrm{Ca}^{2+}$ levels $\left(\left[\mathrm{Ca}^{2+}\right]_{\mathrm{I}}\right)$ in several sequential steps: Hydrolysis of phosphatidylinositol (PI)-4,5-bisphosphate (PIP2) by PLC results in generation of inositol-1,4,5-trisphosphate (IP3); IP3 binds to IP3 receptors (IP3R) in the endoplasmic reticulum (blue compartment) and promotes a brief spike of $\left[\mathrm{Ca}^{2+}\right]_{\mathrm{I}}$ increase by depleting ER $\mathrm{Ca}^{2+}$ stores; and store depletion is sensed by an as-yet-uncharacterized signaling mechanism that triggers a sustained process of "store-operated" $\mathrm{Ca}^{2+}$ entry through CRAC channels in the plasma membrane. $\left[\mathrm{Ca}^{2+}\right]_{\mathrm{I}}$ increases result in activation of many calmodulin (CaM)-dependent enzymes, including the phosphatase calcineurin and the CaM-dependent kinases CaMKII and CaMKIV. Calcineurin dephosphorylates multiple phosphoserines on NFAT, leading to its nuclear translocation and activation. Calcineurin activity is inhibited by the immunosuppressive drugs cyclosporin A (CsA) and FK506, which act as complexes with their intracellular immunophilin receptors cyclophilin and FKBP12, respectively. In parallel, hydrolysis of PIP2 by PLC results in production of diacylglycerols (DAG), which activate RasGRP and protein kinase C (PKC). Receptor activation is coupled to activation of protein tyrosine kinases (PTKs), Ras, MAP kinases (MAPK), and PI-3 kinase (PI3K). MAP kinase activation leads to synthesis and activation of Fos and Jun, the components of the heterodimeric transcription factor AP-1, which then binds cooperatively with NFAT to composite NFAT:AP-1 sites found in the regulatory regions of many NFAT target genes. $\mathrm{Ca}^{2+}$ mobilization is terminated by $\mathrm{Ca}^{2+}$-binding proteins and by $\mathrm{Ca}^{2+}$ ATPases in the ER and plasma membranes, which pump Ca ${ }^{2+}$ back into ER stores and out of the cell, respectively. The ER enzyme is inhibited by thapsigargin, which depletes ER Ca ${ }^{2+}$ stores and activates CRAC channels in the absence of receptor stimulation. In neurons and vascular smooth muscle cells, NFAT is selectively activated by $\mathrm{Ca}^{2+}$ influx through $\mathrm{L}_{\text {-type }} \mathrm{Ca}^{2+}$ channels (LTCC; Graef et al. 1999; Stevenson et al. 2001). The underlying mechanism is not understood. Potentially, calcineurin and NFAT could be localized to the vicinity of plasma membrane signaling complexes containing LTCC, NMDA receptors, and scaffold/adapter proteins such as PSD95 and AKAP-79. Alternatively, as suggested for CREB activation, the mechanism could involve selective activation of MAPK pathways via calmodulin bound to LTCC (Dolmetsch et al. 2001).

The implication is that several constitutive kinases cooperate to maintain the inactive, phosphorylated state of NFAT in resting cells; similarly, several inducible and/or constitutive kinases may act to rephosphorylate NFAT that has been dephosphorylated during cell activation. Sequence comparisons show that the SRR-1 region is extended in NFAT2-4, whereas the SP-2 and SP-3 motifs are truncated in NFAT3 (Okamura et al. 2000); thus, different NFAT proteins may be regulated by overlapping but distinct sets of constitutive and inducible kinases. Because phosphorylation specifies the subcellular distribution, DNA binding affinity, and transcriptional activity of NFAT (Shaw et al. 1995; Beals et al. 1997a; Okamura et al. 2000; Porter et al. 2000; Neal and Clipstone 2001), regulation of each NFAT protein by mul- tiple kinases should in theory permit an almost continuous modulation of the level of NFAT activation.

Although several NFAT kinases have been identified, an integrated picture of NFAT phosphorylation has not yet emerged. CK1 and GSK3 are constitutive NFAT kinases that promote NFAT nuclear export (Beals et al. 1997b; Zhu et al. 1998); phosphorylation by GSK3 requires prior phosphorylation by a priming kinase such as PKA (Sheridan et al. 2002). Consistent with its known sequence preference (Harwood 2001), GSK3 phosphorylates the SPxx motifs of NFAT2 (Beals et al. 1997b). The MAP kinases $\mathrm{p} 38$ and JNK are inducible kinases that promote NFAT nuclear export, by selectively phosphorylating NFAT proteins at the Ser-Pro (SP) sequences at the beginning of their SRR-1 regions: JNK1 phosphory- 
Hogan et al.

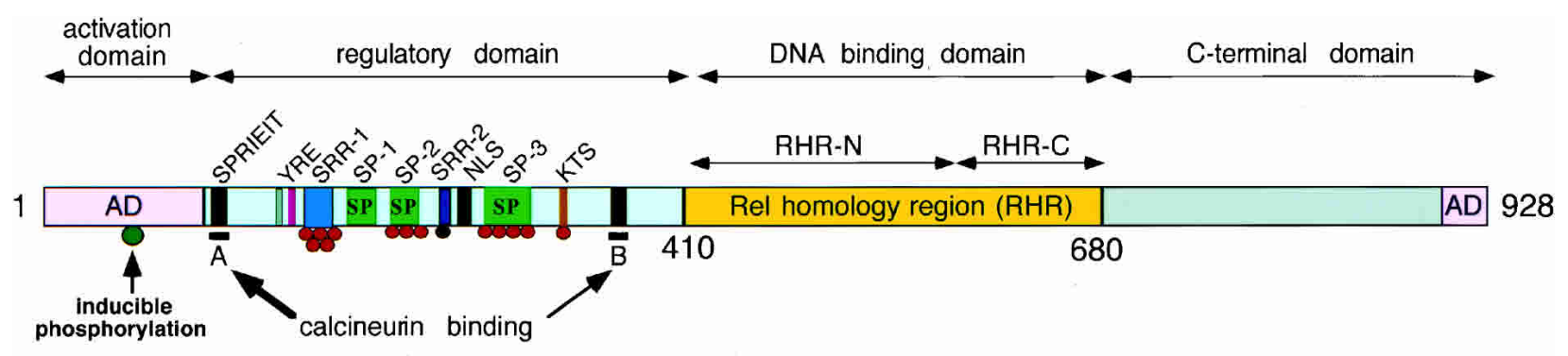

\author{
Serine-rich gatekeeper region: (SRR-1) YREPLCLSPASSGSSASFISD \\ Calcineurin-binding region $A$ \\ PXIXIT (SPRIEIT, CPSIRIT, CPSIQIT) \\ Second SPxx repeat motif (SP-2): \\ SPRTSSPIMSPRTSLAEDS \\ Third SPxx repeat motif (SP-3): \\ SRR-2/ NLS: \\ SPQRSRSPSPQPSPHVAPQDD \\ RPASRSSSPGAKRRHS
}

Calcineurin-binding region $\mathrm{B}$

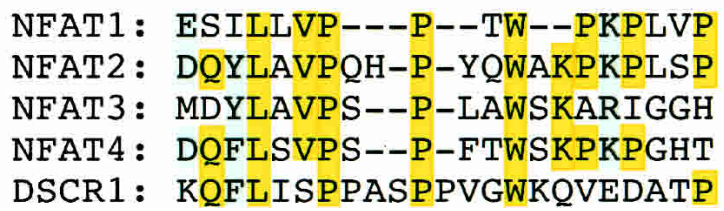

Figure 2. The NFAT regulatory domain: sites of phosphorylation and interaction with calcineurin. (Top) Overall structure of NFAT proteins. The diagram is based on murine NFAT1 (Okamura et al. 2000). Regulatory-domain phosphorylations in conserved sequence motifs are shown as circles below the motif. Red circles indicate phosphate groups that are removed by calcineurin, whereas the black circle in the SRR-2 region is not susceptible to dephosphorylation by calcineurin. The two regions involved in contacting calcineurin are indicated. Region A is the PxIxIT sequence found in all NFAT proteins, and region B has been defined in NFAT2 and in NFAT4. (AD) Activation domains; (NLS) nuclear localization signal in the regulatory domain. A subsidiary NLS is located in the RHR-C domain (Beals et al. 1997a). (Middle) Sequences of phosphorylated motifs in murine NFAT1, with phosphorylated residues indicated in blue boxes, other conserved residues shaded in yellow, and the core of the nuclear localization signal (KRR) shown in bold. The phosphorylated residues in the SPxx, SRR-2/NLS, and KTS motifs were identified by mass spectrometry; those shown as phosphorylated in the SRR-1 region indicate one possible arrangement of the five residues known to be phosphorylated, among the seven serines present in the motif (Okamura et al. 2000). (Bottom) Sequences of the calcineurin-binding region B of NFAT2 and NFAT4 aligned with the corresponding sequences of other NFAT proteins and the similar sequence in DSCR1. All sequences are from the human proteins.

lates NFAT2 and NFAT4, whereas p38 selectively targets NFAT1 and NFAT3 (Chow et al. 1997; Gómez del Arco et al. 2000; Yang et al. 2002). For JNK1, a proposed mechanism is that phosphorylation of the SPRIEIT calcineurin-docking site of NFAT2 blocks the interaction of NFAT2 with calcineurin (Chow et al. 2000).

Selective activation of export kinases explains how individual NFAT proteins might be differentially regulated in a single cell type. For instance, developing skeletal muscle cells show selective nuclear localization of NFAT2 in conjunction with cytoplasmic localization of NFAT1 and NFAT4 (Abbott et al. 1998). This behavior is also observed in $\mathrm{T}$ cells stimulated for 5-6 h through the T-cell receptor (TCR; Loh et al. 1996a); it could occur through activation of export kinases selective for NFAT1 and/or inhibition of export kinases selective for NFAT2. In another illustration, NFAT3 in hippocampal neurons remained nuclear for 60-90 min after brief depolarization with high $\mathrm{K}^{+}$, reflecting either inhibition of an NFAT3 kinase or un- usually prolonged calcineurin activation /Graef et al. 1999). In T cells, T-cell receptor stimulation is coupled to $\mathrm{Ca}^{2+} /$ calcineurin signaling and NFAT nuclear import, where as stimulation through the costimulatory receptor CD28 potentiates activation of the PI-3 kinase pathway and hence the kinase Akt/PKB (Parry et al. 1997; Cantrell 2002). Akt promotes an inhibitory phosphorylation of GSK3 (Cross et al. 1995). The net result is that CD28 costimulation, by activating Akt, inhibits GSK3 and therefore NFAT nuclear export, prolonging the duration of NFAT nuclear residence in T cells stimulated through both the TCR and $\mathrm{CD} 28$, relative to $\mathrm{T}$ cells stimulated through the TCR alone (Diehn et al. 2002).

As with other transcription factors, NFAT transcriptional activity may be regulated by modification of the transactivation domains. This aspect has not been studied extensively, however. Inducible phosphorylation of the transactivation domain has been observed for NFAT1, and mutation of the modified serines eliminates 
transcriptional activity (Okamura et al. 2000). The Cot1 and Pim 1 kinases potentiate transactivation by NFAT1 and NFAT2, respectively (de Gregorio et al. 2001; Rainio et al. 2002), but it is not known whether this occurs through direct phosphorylation of the NFAT transactivation domain.

\section{Other considerations}

Multisite phosphorylation: The phosphorylation status of the regulatory domain specifies DNA-binding affinity as well as relative exposure of nuclear localization (NLS) and nuclear export (NES) sequences (Shaw et al. 1995; Beals et al. 1997a; Okamura et al. 2000; Porter et al. 2000; Neal and Clipstone 2001), but how this occurs has not yet been elucidated at a structural level. The most likely hypothesis is that dephosphorylation facilitates a global conformational switch of NFAT from an inactive to an active conformation /Okamura et al. 2000), possibly by interrupting multiple interactions of phosphorylated motifs with complementary sequences on NFAT itself and/or on partner proteins (Beals et al. 1997a; Porter et al. 2000; Neal and Clipstone 2001). Multisite phosphorylation is known to increase the sensitivity of biochemical processes to their signaling inputs (e.g., see Nash et al. 2001; Orlicky et al. 2003). In a mathematical model of the NFAT conformational switch, Salazar and Höfer (2003) addressed the longstanding puzzle of why there are so many phosphorylation sites on NFAT, by calculating the sensitivity of NFAT to changes in calcineurin activity as a function of the number of dephosphorylations required to induce the active conformation. If the number of dephosphorylations was set at the 13 sites actually observed for NFAT1 (Okamura et al. 2000), the dose-response curve was steep and highly cooperative, defining a threshold of calcineurin activity below which NFAT remained inactive and above which full activation was obtained. In contrast, if dephosphorylation at only 1-2 sites was postulated to be sufficient for full activation, a very shallow dose-response curve was obtained (i.e., even a large increase in calcineurin activity induced only a small increase in NFAT activity; Salazar and Höfer 2003).

Nuclear transport: The nuclear-cytoplasmic ratio attained by an NFAT protein reflects not only the balance of calcineurin and NFAT kinase activities, but also the summation of import and export rates of NLS-exposed and NES-exposed forms. The export kinetics of NFAT lag behind the kinetics of its rephosphorylation in the nucleus (Loh et al. 1996a,b), possibly because the phosphorylated SP motifs need to be restored to the proper configuration by the phosphoSP-selective prolyl isomerase Pin 1 (W. Liu et al. 2001). The import receptor for NFAT has not been definitively identified, although a potential candidate is Rch1 (Torgerson et al. 1998); the export receptor is most likely Crm1, the target of the nuclear export inhibitor leptomycin B (Klemm et al. 1997; Kehlenbach et al. 1998), which preferentially binds phos- phorylated NFAT1 (Okamura et al. 2000). It is not clear whether phosphorylated NFAT exposes an intrinsic NES (as suggested for NFAT2; Klemm et al. 1997), or whether NES function is conferred by proteins such as 14.3.3 that bind to the phosphorylated form (as suggested for NFAT3; Chow and Davis 2000). The putative NES of 14.3.3 was shown to function globally in ligand binding rather than directly mediating nuclear transport (Brunet et al. 2002), indicating that a different NES is needed. Whatever the specific mechanism, import/export kinetics will contribute to averaging NFAT activity under conditions of intermittent stimulation.

Autoregulation of NFAT2: The shortest isoform of NFAT2 (NFATc/A) is induced in a CsA-sensitive manner by NFAT itself, in a process suggested to constitute a positive autoregulatory loop (Zhou et al. 2002). This protein is generated through utilization of a distinct inducible promoter that is preferentially coupled to the most proximal polyadenylation site /Chuvpilo et al. 1999). As a result, NFATc/A lacks the entire $\mathrm{C}$-terminal domain and contains an alternate $\mathrm{N}$-terminal domain, which differs from that of other NFAT isoforms in that it is not highly acidic. Positive autoregulation of one isoform of a transcription factor is a familiar strategy in cell lineage commitment, because it ensures that high levels of the factor are available to maintain the committed state (Davidson 2001). The fact that an NFAT2 isoform is the only NFAT protein subject to positive autoregulation explains why NFAT2 is most often identified as the major NFAT protein participating in a biological response (e.g., Th2 and osteoclast differentiation; Glimcher and Murphy 2000; Takayanagi et al. 2002). This important aspect of gene regulation by NFAT is discussed more extensively below.

Signaling pathways that affect AP-1 activity: As noted below, the AP-1 transcription factor is a major transcriptional partner of NFAT (Macián et al. 2001). Classically, AP-1 consists of heterodimers of Fos- and Junfamily proteins: Fos proteins do not dimerize with one another, and Jun dimers bind DNA with lower affinity than Fos-Jun (Chinenov and Kerppola 2001; Jochum et al. 2001; Mechta-Grigoriou et al. 2001). Because AP-1 activity is also modulated by diverse signaling inputs (Davis 2000), NFAT:AP-1-dependent transcription integrates a very large number of signaling pathways and processes: The magnitude and kinetics of $\left[\mathrm{Ca}^{2+}\right]_{\mathrm{I}}$ increases; the level of calcineurin activity; the activities of kinases that modulate NFAT nuclear export, DNAbinding, or intrinsic transcriptional activity; the activities of PKC/MAP kinase pathways and other signaling pathways that influence Fos-Jun synthesis and activation; and the integrity of cytoskeletal interactions and other intracellular processes that have more global effects. In consequence, NFAT:AP-1-based reporter assays are ideal for overall evaluations of cellular signaling: In T cells stimulated through antigen and costimulatory receptors, NFAT: AP-1 reporter activity is influenced by overexpression of wild-type or mutant versions 
Hogan et al.

of a multitude of signaling proteins (e.g., see Sosinowski et al. 2000; Kaminuma et al. 2001). In other cell types, $\mathrm{Ca}^{2+}$ mobilization is coupled to stimulation through receptor tyrosine kinases and G-protein-coupled receptors, and NFAT reporters would be useful in an unbiased quest for signaling molecules in these pathways as well.

\section{Diverse modes of DNA binding by NFAT}

\section{Structural relation to the Rel/NFкB family}

All five proteins of the NFAT family, NFAT1-NFAT4 and NFAT5/TonEBP, may be classified as members of the extended NFкB/Rel family (Fig. 3). The classification is based on the structural similarities of their DNA-binding domains, also known as Rel homology regions (RHR). The canonical mode of DNA binding by the RHR has been well characterized in the structures of several NFкB-DNA complexes (Ghosh et al. 1995; Muller et al. 1995): The RHR contains two functionally distinct domains, an N-terminal specificity domain (RHR-N) that makes base-specific DNA contacts, and a C-terminal domain involved in dimer formation and I $\mathrm{B}$ binding (RHRC; Fig. 4; Huxford et al. 1998; Jacobs and Harrison 1998). Of the five NFAT proteins, NFAT5/TonEBP shows the highest degree of structural similarity to $\mathrm{NF} \kappa \mathrm{B}$, forming a symmetric dimer with a striking resemblance to the NFкB-DNA complex (Fig. 4, cf. A and B; Stroud et al. 2002). The detailed dimerization interactions mediated by the RHR-C of NFAT5 are very similar to those observed in NFкB, but the unique feature of the NFAT5 dimer-DNA complex is a second dimer interface formed by the E'F loop of the RHR-N domain (Fig. 4B). As a result, NFAT5 completely encircles its DNA (Fig. 4B), explaining the unusually slow dissociation kinetics of the NFAT5-DNA complex (Stroud et al. 2002).

Two NFAT1 dimer complexes, bound to $\kappa \mathrm{B}$ sites from the $I L-8$ promoter and the HIV-1 LTR, have recently been characterized at the structural level (Giffin et al. 2003; Jin et al. 2003). As in the NFAT5 and Rel dimer complexes, the NFAT1 dimer interface resides in the C-terminal region of the RHR (Fig. 4C,D). However, this interface is surprisingly different from the symmetric and hydrophobic RHR-C dimer interface seen in NFAT5 and NFкB: It is asymmetric and largely hydrophilic, and involves residues not used in Rel or NFAT5. The interface is essentially identical in the NFAT 1 dimers bound to the IL- 8 and HIV-1 LTR $\kappa$ B sites, but these two NFAT1 dimer complexes differ significantly in their RHR-N interactions and hence their overall conformation (Fig. 4, cf. C and D). Specifically, the NFAT1 dimer on the HIV-1 LTR $\kappa$ B site completely encircles the DNA through E'F-loop interactions in the RHR-N domain, in a manner similar to that seen in the NFAT5-DNA complex (Fig. 4, cf. B and C). In the ternary NFAT/Fos-Jun/ DNA complex (see Fig. 5; Chen et al. 1998), the E'F loop constitutes the major binding site for Fos-Jun, emphasizing the versatility of this protein surface in promoting assembly of distinct transcription complexes containing NFAT.

DNA binding by NFAT dimers is a versatile mechanism permitting homo- and heterodimer formation at response elements with varying sequences and spacing. Many of the RHR-C interface residues observed in the NFAT1 dimer are conserved in NFAT2 and NFAT4; in cases where the residues differ, interface complementarity appears to be maintained by covariation of the interacting residues. NFAT3 is a potential exception because it has significantly different residues at positions

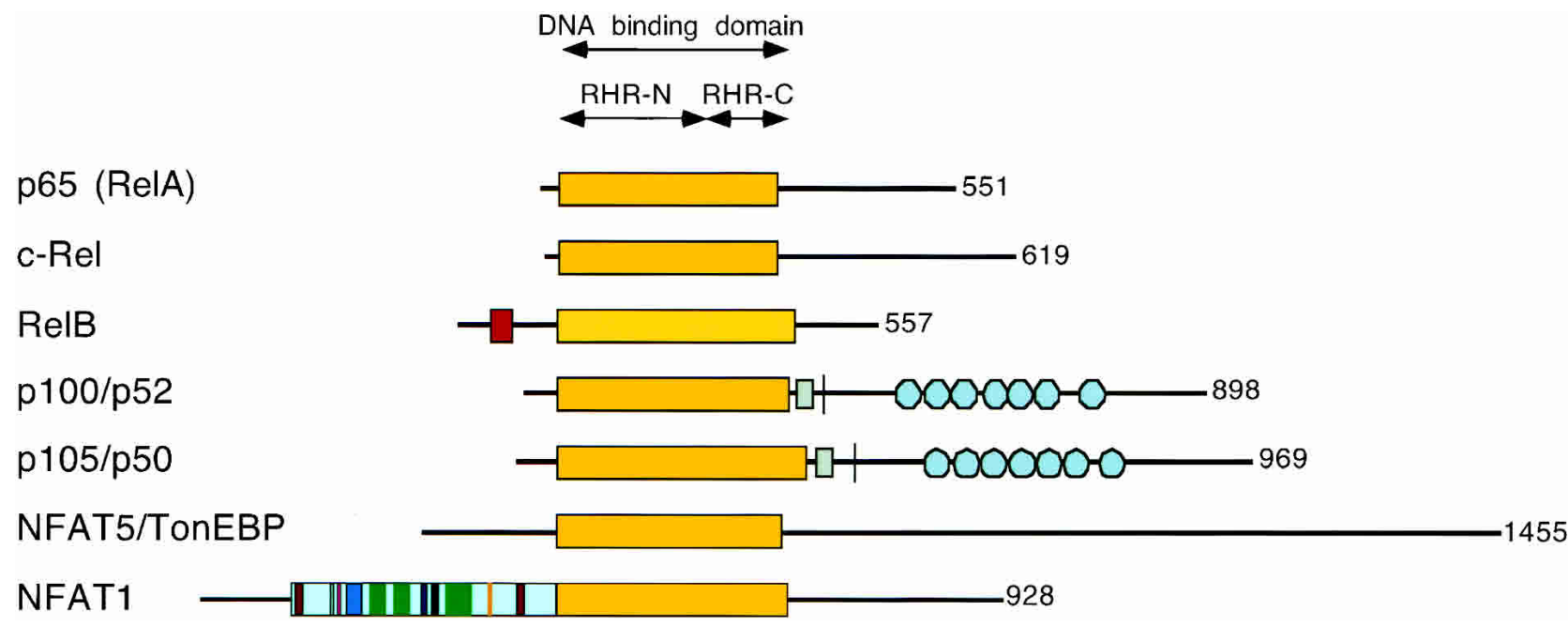

Figure 3. Alignment of NFKB/Rel proteins with NFAT5 and NFAT1 (Rel alignment modified from Rothwarf and Karin 1999). The DNA-binding domains are aligned, and the N- and C-terminal portions of the Rel homology region are indicated (RHR-N and RHR-C, respectively). A leucine zipper motif in RelB is shown as a red box. In p100 and p105, serine-rich regions and ankyrin repeats are shown as gray boxes and blue circles, respectively, and the site of cleavage to p52 or p50 is indicated by a vertical line. The NFAT regulatory domain is patterned as in Figure 2. 
A
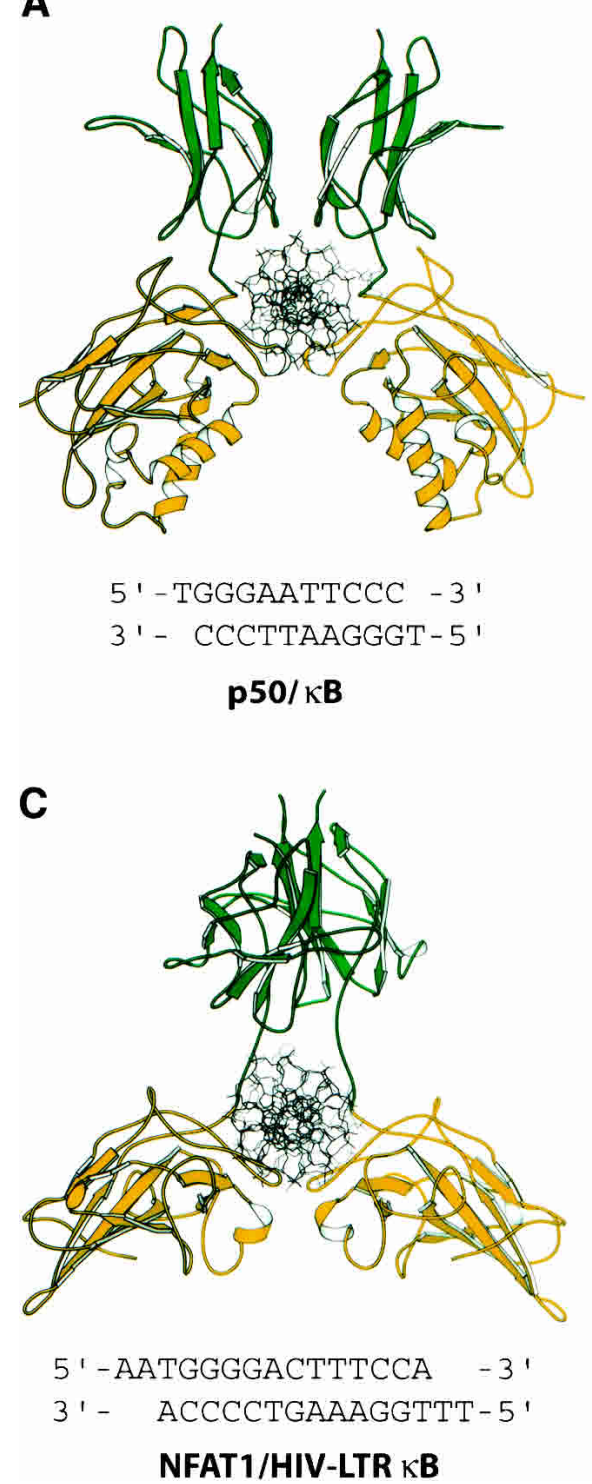

B

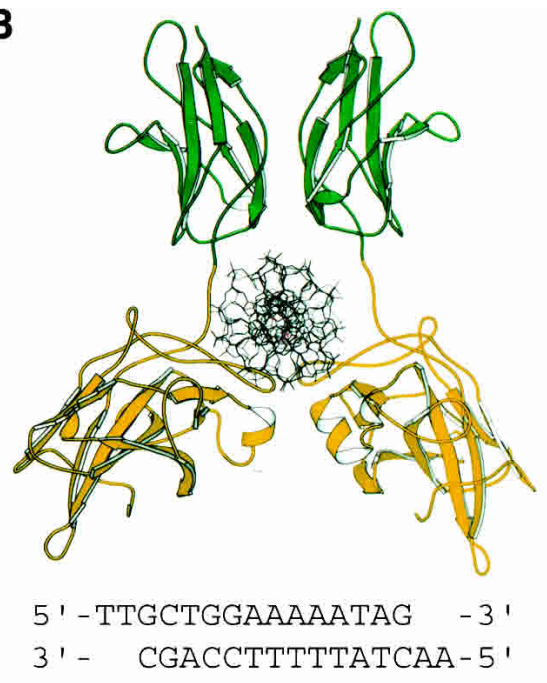

NFAT5/TOnE

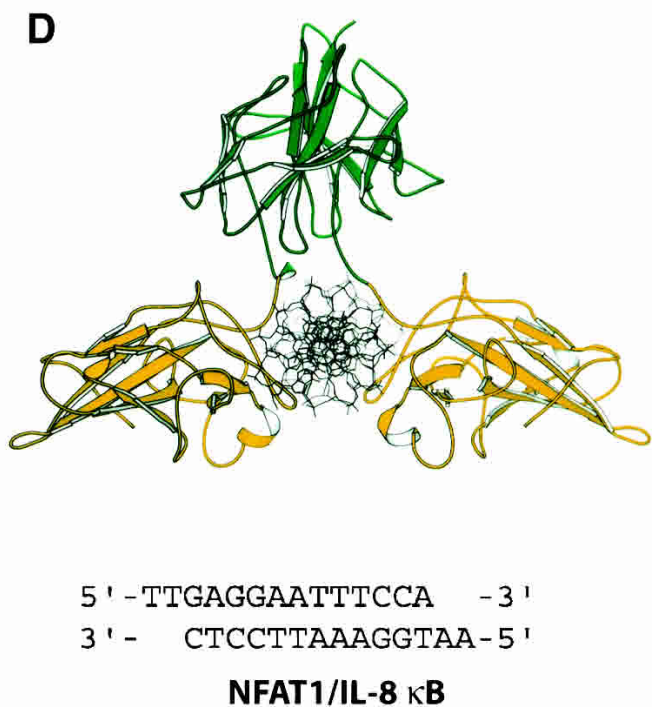

Figure 4. Crystal structures of NFAT and Rel dimeric protein/DNA complexes. The proteins are shown in ribbon style, with the RHR-N domain in green and the RHR-C domain in yellow, and the DNA is drawn in stick model. (A) NFkB p50 homodimer bound to a $\mathrm{\kappa B}$ site. (B) NFAT5/TonEBP bound to a tonicity response element. (C) The NFAT1 dimer bound to the $\mathrm{\kappa B}$ site from the HIV-1 LTR (identical in sequence to the murine Ig $\mathrm{\kappa B}$ site). $(D)$ The NFAT1 dimer bound to a $\mathrm{\kappa B}$ site similar to that in the human $I L-8$ promoter. In $B$ and $C$, the E'F loop of each protein partner extends toward the midline below the DNA helix and forms a second dimer interface. The DNA sequence of each complex is shown below the structure.

corresponding to those in the NFAT1 dimer interface. Modeling studies suggest that NFAT1, NFAT2, and NFAT4 would be capable of forming both homo- and heterodimers on $\kappa \mathrm{B}$-like DNA sites. These interactions are likely to be confined to the NFAT family, however: Although NFAT1-4, NFAT5/TonEBP, and NFкB/Rel dimers can all bind similar DNA elements, their modes of dimerization are different (Fig. 4) and they respond to distinct intracellular signals (López-Rodríguez et al. 2001), suggesting that mixed NFAT/NFAT5/NFKB dimers do not normally occur.

The $\kappa 3$ site of the TNF $\alpha$ promoter (TGGAGAAACCC) is a good example of a physiological $\mathrm{\kappa B}$-like site to which
NFAT binds as a dimer (Goldfeld et al. 1993; McCaffrey et al. 1994). It resembles the 10-bp кB site used for structure determination by Giffin et al. (2003). Binding is nucleated at the half-site shown in bold, but the other half-site (underlined) is quickly occupied at low NFAT concentrations (McCaffrey et al. 1994). Mutation of NFAT contact residues impairs $T N F \alpha$ promoter activity in reporter assays in T and B cells (Goldfeld et al. 1993). Sites that can bind both NFAT and NFkB have been identified in the HIV-1 LTR and in the $I L-8, I L-13$, and GMCSF promoters (for review, see Rao et al. 1997; Macián et al. 2001); which factors actually occupy the site in vivo depends on the cell type being examined and the specific 
conditions of stimulation. Because NFAT is not an obligate dimer and the cooperativity of the DNA-bound dimer is less than that observed for the NFAT:AP-1 complex, it is plausible that some dimeric elements may bind NFAT either as a monomer or as a dimer depending on the available concentration of this transcription factor in the nucleus.

\section{Cooperative interactions with Fos-Jun proteins} in the nucleus

NFAT1-4 proteins form strong cooperative complexes on DNA with the unrelated transcription factor AP-1 (Fos-Jun dimers; Fig. 5; Chen et al. 1998; Macián et al. 2001). The ternary NFAT:Fos:Jun complexes serve as signal integrators for two diametrically different signaling pathways, the calcium/calcineurin pathway that activates NFAT and the phorbol ester-responsive MAP kinase pathway that promotes the synthesis and activation of Fos and Jun family proteins. The NFAT:Fos:Jun complexes contact an $\sim 15$-bp stretch of DNA, in which the NFAT and AP-1 elements are precisely apposed to create a true "composite" site (Fig. 5; Chen et al. 1998). The residues involved in Fos-Jun contact are located largely in the N-terminal RHR domains of NFAT, and form an extensive network of mostly polar interactions with residues in the basic leucine zipper regions of Fos and Jun; they are not strong enough to stabilize the NFAT:AP-1 complex in the absence of DNA. The interacting residues are almost completely conserved in NFAT1-4 but are absent from NFAT5 (López-Rodríguez et al. 1999), indicating that the ability to cooperate with Fos and Jun was a late evolutionary development.

A wide range of composite binding sites is observed in the regulatory regions of NFAT target genes (Kel et al. 1999; for review, see Rao et al. 1997; Macián et al. 2001). By analyzing a set of 11 experimentally verified NFAT: AP-1 composite sites, Kel et al. (1999) demonstrated that the free energy of NFAT and AP-1 binding to their respective subsites showed a striking inverse correlation, in that strong NFAT binding tended to be paired with weak AP-1 binding and vice versa (see Table 2). Presumably, the total free energy of binding is maintained within a narrow range because of biological constraints, such as a need for rapid disassembly of NFAT:AP-1-containing transcription complexes when the initiating stimulus decays.

A common feature of natural promoters and enhancers is the presence of multiple binding sites for critical transcription factors (Davidson 2001). This is especially true for NFAT target genes, whose promoters and distal enhancers generally contain multiple NFAT or NFAT:AP-1 sites (Rao et al. 1997; Macián et al. 2001). Could NFAT: AP-1 complexes separated by tens, hundreds, or thousands of base pairs interact through their RHR-C dimer interfaces? In the ternary NFAT:AP-1/DNA complex, the RHR-C residues involved in NFAT dimerization are exposed to solvent but lie in a deep groove between the RHR-N and RHR-C, sterically precluding such interactions. However, given the multiple orientations of RHR-C observed in different NFAT complexes, the RHR-C in the NFAT:AP-1 complex could conceivably

Table 2. Sites showing cooperative binding of NFAT and AP-1 in binding assays in vitro ${ }^{a}$

\begin{tabular}{|c|c|c|c|c|c|}
\hline \multirow[b]{2}{*}{ Regulatory element } & \multirow[b]{2}{*}{$\mathrm{Sp}^{\mathrm{b}}$} & \multirow[b]{2}{*}{ Composite Site $^{c}$} & \multicolumn{2}{|c|}{ Independent binding ${ }^{\mathrm{d}}$} & \multirow[b]{2}{*}{ Reference } \\
\hline & & & NFAT & AP-1 & \\
\hline IL2 ARRE2 (-180) & $\mathrm{h}$ & AGGAAAaacTGttTCA & yes & no & Jain et al. 1993b \\
\hline & $\mathrm{m}$ & AGGAAAattTGttTCA & yes & no & Jain et al. 1992, 1993a,b \\
\hline IL5P & $\mathrm{h}$ & TGGAAAcatTtAGTtt & & & \\
\hline & $\mathrm{m}$ & TGGAAAcccTGAGTtt & no & no & Lee et al. 1995 \\
\hline GM-CSF GM330 & $\begin{array}{l}\mathrm{h} \\
\mathrm{m}\end{array}$ & $\begin{array}{l}\text { cGGAGccccTGAGTCA } \\
\text { TGagGccctTGAGTCA }\end{array}$ & no & weak & Cockerill et al. 1995 \\
\hline GM-CSF GM420 & $\begin{array}{l}\mathrm{h} \\
\mathrm{m}\end{array}$ & $\begin{array}{l}\text { TGGAAAgatgacaTCA } \\
\text { TaGAAAgatgacaTCA }\end{array}$ & yes & weak & Cockerill et al. 1995 \\
\hline GM-CSF GM550 & $\begin{array}{l}\mathrm{h} \\
\mathrm{m}\end{array}$ & $\begin{array}{l}\text { AGGAAAgcaaGAGTCA } \\
\text { AGGAAAgcagaggccccaGAGTCA }\end{array}$ & no & no & Cockerill et al. 1995 \\
\hline $\operatorname{IL} 4(-88 \text { to }-61)^{\mathrm{e}}$ & $\begin{array}{l}\mathrm{h} \\
\mathrm{m}\end{array}$ & $\begin{array}{l}\text { TGGAAAttttcgTtACaCc } \\
\text { TGGAAAattttaTtACaCc }\end{array}$ & yes & no & Rooney et al. 1995 \\
\hline
\end{tabular}

${ }^{a}$ Cooperative binding is defined as significantly increased binding of NFAT or AP-1 to the regulatory element in the presence, compared with the absence, of its partner protein. The binding assays used were in vitro footprinting (Rooney et al. 1995) and electrophoretic mobility shift assays (all others).

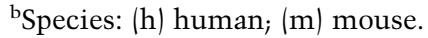

'Boldface indicates oligonucleotide used in referenced study. Sequences in capital letters denote identity with consensus NFAT (WGGARA) or AP-1 (TGASTCA) sites.

${ }^{\mathrm{d}}$ Independent binding: binding in the absence of partner.

${ }^{\text {e}}$ The mouse GM550 element, and the human and mouse IL-4 elements, do not show the strict spacing between the NFAT and AP-1 sites assumed from the crystal structure to be essential for optimal NFAT:AP-1 cooperation (Fig. 5). Cooperative binding on the IL-4 element was demonstrated by footprinting with recombinant Fos, Jun, and NFAT. In the case of GM-CSF, the GM330, GM420, and GM550 elements are part of a single enhancer region in which they most likely have redundant functions; there is also a fourth element that does not show cooperative binding. Thus, the difference in spacing between the human and mouse GM550 elements could reflect the fact that this element is not essential for enhancer function, even in humans. 

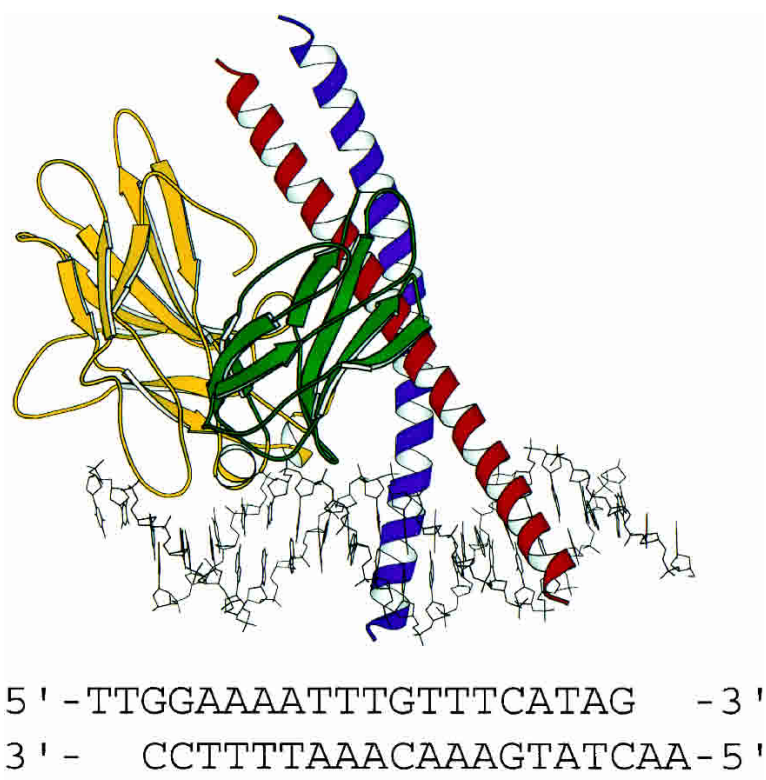

NFAT1/Fos-Jun/ARRE2

Figure 5. The crystal structure of the NFAT/Fos-Jun/DNA complex bound to the ARRE- 2 site of the $I L-2$ promoter (Chen et al. 1998). The structure of this complex is a striking illustration of signal integration by NFAT and AP-1. Two bifurcating signal transduction pathways converge on the cooperative complex: The NFAT component is activated by $\mathrm{Ca}^{2+} /$ calcineurin signaling, while the AP-1 component (Fos-Jun) is activated by PKC/MAP kinase signals.

rearrange to allow RHR-C interface formation, thus promoting the assembly of long-range, higher-order NFAT: AP-1 complexes. Further versatility would arise from utilization of different NFAT-Fos-Jun combinations. With the advent of new reagents ("tethered AP-1" dimers; Bakiri et al. 2002), constitutively active NFAT proteins (Macián et al. 2002; Monticelli and Rao 2002; Porter and Clipstone 2002), and mutant NFAT proteins impaired for RHR-N or RHR-C-mediated dimer formation (Giffin et al. 2003; Jin et al. 2003), the functions of different NFAT:AP-1 combinations and higher-order NFAT:AP-1 complexes may be explicitly assessed.

\section{Interactions with other transcription factors}

In addition to its interaction with AP-1, NFAT engages in direct protein-protein interactions and/or influences transcription synergistically with several families of transcription factors: proteins such as Maf, ICER, and p21SNFT that belong to the same basic region-leucine zipper (bZIP) family as AP-1 (Ho et al. 1996; Bodor et al. 2000; Bower et al. 2002); the zinc finger proteins GATA (see below), and EGR (Decker et al. 1998, 2003); the helix-turn-helix domain proteins Oct, HNF3, and IRF-4 (Fürstenau et al. 1999; Bert et al. 2000; Hu et al. 2002; Rengarajan et al. 2002); the MADS-box protein MEF2 (for review, see Olson and Williams 2000; Crabtree and Olson 2002; McKinsey et al. 2002); and the nuclear receptor
PPAR- $\gamma$ (X.Y. Yang et al. 2000). For transcriptional partners other than AP-1, it is not known whether the synergy with NFAT occurs in the context of true "composite" regulatory elements that have a defined geometry and spatial orientation for cooperative binding of NFAT and these partner proteins.

bZIP proteins other than Fos and Jun: The interaction of NFAT with Fos-Jun proteins cannot be detected in solution but is remarkably cooperative on DNA (Jain et al. 1992, 1993a,b; Chen et al. 1995; Cockerill et al. 1995). In contrast, another bZIP protein, Maf, was identified as a transcriptional partner for NFAT based on a purely protein-protein interaction in a yeast two-hybrid screen (Ho et al. 1996). In cotransfection assays, NFAT and Maf synergistically activated a reporter plasmid driven by the $I L-4$ promoter. Although cooperative NFAT:Maf binding was not observed on the site originally investigated because of the inverse orientation of the NFAT site relative to the Maf binding site (Ho et al. 1996), Maf and NFAT could conceivably cooperate at classical NFAT:AP-1 sites (Fig. 6). The key NFAT-binding residues in Jun are not all conserved in Maf, but the modeled NFAT-Maf interface has good shape and chemical complementarity. Mutagenesis studies indicate that Arg 285 of Jun is critical for NFAT binding (Peterson et al. 1996); in the modeled Maf/NFAT interface, a Gln residue in this position can make similar contacts with NFAT.

Two other small bZIP proteins, ICER and p21SNFT, have been reported to bind NFAT and inhibit NFATdependent transcription (Bodor et al. 2000; Bower et al. 2002). Again, ICER does not conserve all the critical NFAT-binding residues in Jun, but the NFAT:ICER interface has a plausible level of complementarity. In fact, the Tyr residue in ICER that corresponds to Arg 285 in Jun could potentially interact with NFAT even more strongly (Fig. 6). p21SNFT binds NFAT mainly as a heterodimer with Jun (Bower et al. 2002), and it is therefore expected that the binding interactions are mostly mediated by Jun and will be similar to that seen in the NFAT/ Fos-Jun/DNA complex.

IRF and EGR proteins: NFAT cooperates with IRF4 at the $I L-2$ and $I L-4$ promoters (Hu et al. 2002; Rengarajan et al. 2002) and with EGR-1 at the $I L-2$ and $T N F-\alpha$ promoters (Decker et al. 1998, 2003). These interactions are not well characterized-the interacting domains have not been delineated, and composite DNA elements have not been defined. In an IRF-4/NFAT complex modeled on a putative composite site from the $I L-4$ promoter $(\mathrm{Hu}$ et al. 2002), IRF-4 and NFAT can potentially bind DNA simultaneously, and their DNA binding domains can interact; similarly, an EGR-1/NFAT complex modeled on a site from the TNF- $\alpha$ promoter (Decker et al. 2003) allows simultaneous DNA binding with direct contact between the RHR of NFAT and the zinc finger domain of EGR-1 (LC; data not shown). Although the flexible conformation of the RHR-C poses uncertainty in modeling these higher-order transcription complexes, it also increases the likelihood that NFAT could interact with a variety of partners on different composite sites.

GATA proteins: Cooperation of NFAT with GATA 
Hogan et al.

Figure 6. The bZIP domains of Maf and ICER may bind the E'F loop of NFAT. (Top) Detailed interactions between NFAT and Jun. (Bottom) Sequence alignment between human c-Jun, c-Maf, and ICER. The colored blocks indicate residues in Jun that bind NFAT. The substitutions of E284, R285, and K292 of Jun with Gln, Gln, and Glu in Maf do not disrupt the interface hydrogen-bonding pattern significantly. The replacement of R285 of Jun by Tyr in ICER may increase the interface van der Waals contacts. R288 of Jun makes several hydrogen bonds to NFAT, whereas the corresponding Val of Maf and Cys of ICER could make van der Waals contacts to T533 of NFAT.
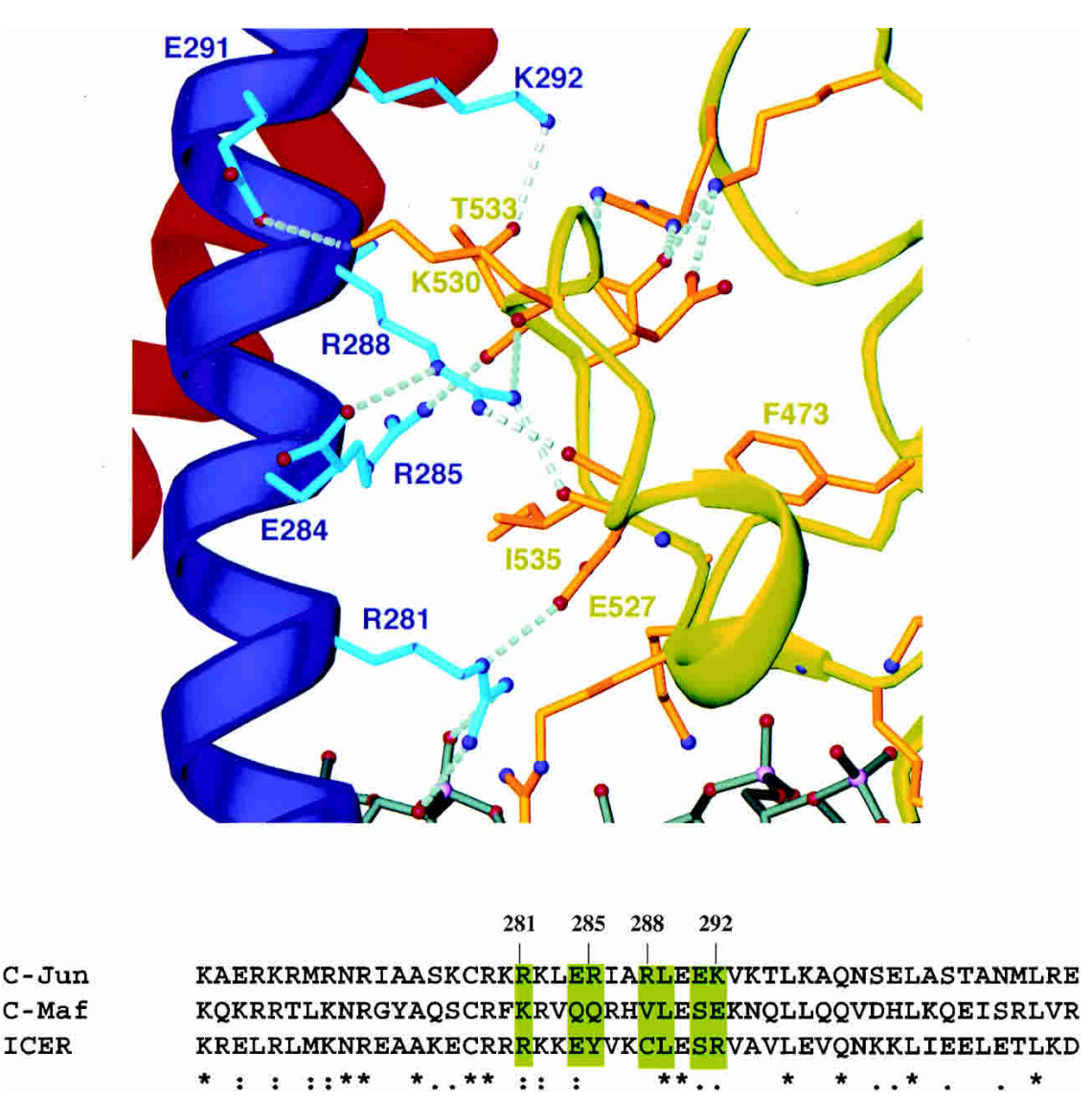

C-Jun C-Maf ICER family members has been observed in many systems (see Table 3). NFAT:GATA cooperation has been established by synergistic activation of reporter plasmids (Molkentin et al. 1998; Morimoto et al. 2001; Avni et al. 2002; Nemer and Nemer 2002; Wada et al. 2002) as well as by direct binding of RHR-C of NFAT3 to a DNA-binding "bait" fragment of GATA4 in a yeast two-hybrid assay (Molkentin et al. 1998). There is evidence for preferential interactions involving the endogenous proteins. In coimmunoprecipitation experiments using a skeletal muscle cell line, GATA2 bound NFAT2 but not NFAT1 (Musaro et al. 1999). There is no overlap between NFAT:GATA and NFAT-AP-1 interaction surfaces, consistent with involvement of RHR-C and RHR-N, respectively. An NFAT1 protein bearing mutations in three key Fos-Juninteracting residues that abrogated the ability of NFAT1 to cooperate with AP-1 was as effective as or more effective than wild-type NFAT1 in its ability to synergize functionally with GATA3 in a transient reporter assay in T-cells (Avni et al. 2002). However, sequence inspection of regulatory regions has not led to unambiguous identification of a composite NFAT:GATA element with specific spacing and orientation, and cooperative NFAT:GATA binding on DNA has not been reported (Table 3).

\section{Biological implications}

NFAT1-4 proteins bind DNA as monomers at cognate (GGAA) sites (L. Chen, unpubl.), as dimers at $\kappa$ B-like response elements (Fig. 4), and as cooperative complexes with Fos and Jun at NFAT:AP-1 composite sites (Fig. 5). The general feature of these various complexes is that the DNA-binding interactions and conformations of the NFAT RHR-N are highly conserved, but the conformation of the RHR-C is quite variable. This diversity of binding modes arises, at least in part, from the fact that NFAT is not an obligate dimer; thus, in contrast to Rel and NFAT5 proteins, which are dimers under all circumstances, the RHR-N and RHR-C of NFAT are free to adopt a variety of orientations in different transcription complexes. This remarkable conformational flexibility of NFAT on different DNA sites is likely to facilitate assembly of NFAT into distinct higher-order complexes containing diverse DNA-binding partners, and would be expected to modulate recruitment of specific transcriptional coregulators in different promoter contexts (Lefstin and Yamamoto 1998; Agalioti et al. 2000; Escalante et al. 2002), as illustrated for the POU-domain protein Pit-1 (Scully et al. 2000).

\section{Transcriptional regulation by NFAT}

Strategies for identification of distal regulatory elements that bind NFAT

Although gene expression is ultimately regulated at the proximal promoter, which binds RNA polymerase and the core transcriptional machinery, distal regulatory regions have profound effects on the expression of nearly 
all genes (Davidson 2001). This is illustrated by the fact that the proximal promoter alone rarely supports correct, cell-type-specific expression of a linked reporter gene in transgenic mice-very large regions, amounting to hundreds of kilobases of surrounding DNA, are often needed (Lakshmanan et al. 1999; Yui et al. 2001). The presence of distal regulatory elements is a general feature of NFAT target genes in $\mathrm{T}$ cells; in particular, distal enhancers are present in all cytokine genes that have been examined in sufficient detail, including the $I L-3, G M-C S F, I L-4, I L-10$, and $I F N-\gamma$ genes (Cockerill et al. 1993, 1995; Duncliffe et al. 1997; Agarwal et al. 2000; Avni et al. 2002; Hawwari et al. 2002; S.-H. Im, D.U. Lee, and A. Rao, unpubl.). Distal NFATdependent gene regulatory elements have been located experimentally by hunting for inducible DNase I hypersensitive sites whose induction is blocked by CsA or FK506 (Cockerill et al. 1993, 1995; Duncliffe et al. 1997; Agarwal et al. 2000; Hawwari et al. 2002). These regions often (but not always) correspond to highly conserved noncoding sequences (CNS) identified by comparing the sequences of gene loci in two or more mammalian genomes using Web-based programs such as VISTA (Mayor et al. 2000; Loots et al. 2002; Bray et al. 2003) or PipMaker (Schwartz et al. 2000). This point is illustrated in Figure 7 for the $I L 2, I L-3$, and GM-CSF genes. The enhancers may be located $5^{\prime}$ of the proximal promoter, within intronic regions, or $3^{\prime}$ of the gene; they tend to contain binding sites not only for NFAT, but also for constitutive or lineage-specific transcription factors that confer cell-type specificity of gene expression (Agarwal et al. 2000; Avni et al. 2002; D.U. Lee and A. Rao, unpubl.).

Although bioinformatics comparison of genomic sequences is a useful strategy for identifying regulatory regions, it does not by itself delimit individual transcription-factor-binding sites; pattern-matching programs or visual inspection must be used to search within the conserved area for known binding motifs. Recognition sites for factors with poorly defined binding motifs will not be identified in this way, although, if biological experiments implicate such a factor, a CNS correlated with a DNase I hypersensitive site is an excellent candidate region in which to search for a DNA target. Composite NFAT:AP-1 elements, and indeed all composite DNA elements, present a particular problem for bioinformatics recognition of binding sites on DNA. Because protein-protein interactions contribute to the stability of the cooperative NFAT:AP-1 complex, either NFAT or AP-1 may attach to a suboptimal sequence if the other partner has bound to a high-affinity site. These suboptimal sequences are often recognizable when NFAT/AP-1 binding has been shown experimentally (see Table 2), but are too degenerate to be useful in long-range screens of extended genomic regions. It is important to note, however, that even bioinformatics predictions for easily

Table 3. Functional NFAT:GATA binding sites in genes and NFAT:GATA interactions in cells

\begin{tabular}{|c|c|c|c|c|c|c|}
\hline $\begin{array}{l}\text { Regulatory } \\
\text { region }\end{array}$ & $\begin{array}{l}\text { Cell type } \\
\text { (stimulus) }\end{array}$ & $\begin{array}{c}\text { Location/arrangement of } \\
\text { binding sites }\end{array}$ & NFAT & GATA & Assay for interaction & Reference \\
\hline IL-4 promoter & Th2 cells (TCR) & $\begin{aligned}-180 & <\underline{\mathrm{A}: \mathrm{N}}<7>\underline{\mathrm{GATA}}>3 \\
& >\underline{\mathrm{N}: \mathrm{A}}>-143\end{aligned}$ & NFAT 1,2 & GATA3 & & \\
\hline IL-5 promoter & Th2 cells (TCR) & $\begin{array}{c}-11 \overline{4}>\underline{\mathrm{N}}: \mathrm{A}>28<\underline{\mathrm{GATA}}< \\
5<\underline{\mathrm{A}: \mathrm{N}}<-41\end{array}$ & NFAT 1,2 & GATA3 & & \\
\hline IL-4 enhancer & Th2 cells (TCR) & $\begin{aligned}>\underline{\mathrm{N}}>\overline{1<\mathrm{GATA}}<2 & >\mathrm{GATA}>2>\underline{\mathrm{GATA}}> \\
& 2 \underline{\mathrm{GAT}}>\mathbf{\mathrm { N }}>\end{aligned}$ & NFAT 1,2 & GATA3 & $\begin{array}{l}\text { Synergy in reporter } \\
\text { assay }\end{array}$ & Avni et al. 2002 \\
\hline BNP promoter & $\begin{array}{l}\text { Cardiomyocytes } \\
\quad \text { (angiotensin II) }\end{array}$ & $\underline{\text { NFAT }}-927$; GATA -27 & NFAT3 & GATA4 & $\begin{array}{l}\mathrm{Y} 2 \mathrm{H} \text {, synergy in } \\
\text { reporter assay; } \\
\text { mutation in NFAT } \\
\text { element abrogates } \\
\text { reporter activity }\end{array}$ & $\begin{array}{l}\text { Molkentin et al. } \\
1998\end{array}$ \\
\hline $\begin{array}{l}\text { Adss-1 promoter } \\
\quad(-1.9 \mathrm{~kb})\end{array}$ & $\begin{array}{l}\text { Cardiomyocytes } \\
\text { (angiotensin II or } \\
\text { electrical pacing) }\end{array}$ & $\underline{\text { NFAT }}-556$ & NFAT3 & GATA4 & $\begin{array}{l}\text { Mutations in binding } \\
\text { elements abrogate } \\
\text { reporter activity }\end{array}$ & $\begin{array}{l}\text { Xia et al. 2000; } \\
\text { Wen et al. } 2002\end{array}$ \\
\hline $\begin{array}{l}\text { EDN-1 promoter } \\
\text { (-204 bp) }\end{array}$ & $\begin{array}{l}\text { Cardiomyocytes } \\
\text { ( } \beta \text {-adrenergic } \\
\text { stimuli) }\end{array}$ & $\underline{\text { GATA }}-136$ & NFAT2 & GATA4 & $\begin{array}{l}\text { Co-ip, synergy in } \\
\text { reporter assay }\end{array}$ & $\begin{array}{l}\text { Morimoto et al. } \\
2001\end{array}$ \\
\hline $\begin{array}{l}\text { EDN-1 promoter } \\
(-1.4 \mathrm{~kb})\end{array}$ & $\begin{array}{l}\text { Endocardial } \\
\text { differentiation }\end{array}$ & $\begin{array}{l}-280<\underline{\mathrm{N}}<13<\underline{-260}<-\underline{\text { GATA }}< \\
\quad\end{array}$ & NFAT2 & GATA5 & $\begin{array}{l}\text { Synergy in reporter } \\
\text { assay }\end{array}$ & $\begin{array}{l}\text { Nemer and } \\
\text { Nemer } 2002\end{array}$ \\
\hline $\begin{array}{l}\text { Skeletal muscle } \\
\text { myosin }\end{array}$ & $\begin{array}{l}\text { IGF-1-induced } \\
\text { skeletal muscle } \\
\text { hypertrophy }\end{array}$ & Sites not identified & NFAT2 & GATA2 & $\begin{array}{l}\text { Co-ip, colocalisation } \\
\text { in nuclei of } \\
\text { differentiating cells }\end{array}$ & $\begin{array}{l}\text { Musaro et al. } \\
1999\end{array}$ \\
\hline Sm-MyHC & $\begin{array}{l}\text { Differentiating VSMC } \\
\text { (low serum) }\end{array}$ & Sites not identified & NFAT2 & GATA6 & $\begin{array}{l}\text { Co-ip, synergy in } \\
\text { reporter assay }\end{array}$ & Wada et al. 2002 \\
\hline
\end{tabular}

${ }^{a} \mathrm{~N}: \mathrm{A}$ or A:N, composite NFAT:AP-1 site (underlining indicates binding element) $>\mathrm{N}: \mathrm{A}>,<\mathrm{A}: \mathrm{N}<,<\mathrm{GATA}<$, and so on indicate orientation of sites, numerals between sites indicate numbers of base pairs between the ends of the binding elements; flanking numerals, or numerals following NFAT or GATA, indicate position relative to transcription start site. For the cytokine gene regulatory regions, only a selection of all sites is shown.

Abbreviations: (Adss-1) adenylosuccinate synthetase-1; (BNP) b-type natriuretic peptide; (EDN-1) endothelin-1; (Sm-MyHC) smooth muscle myosin heavy chain; (TCR) T-cell receptor; (VSMC) vascular smooth muscle cells; (Y2H) yeast two-hybrid screen, (co-ip) coimmunoprecipitation. 
Hogan et al.

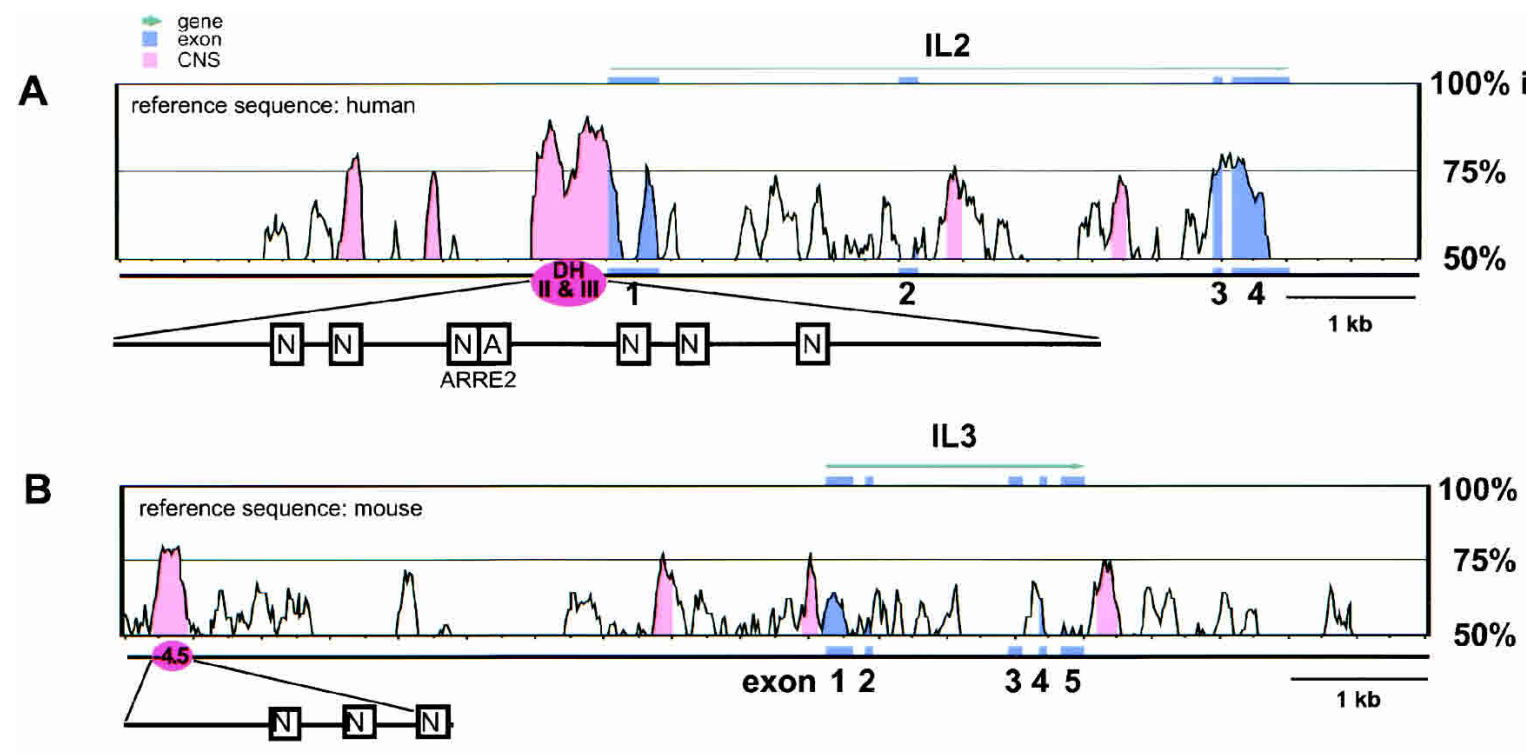

GM-CSF

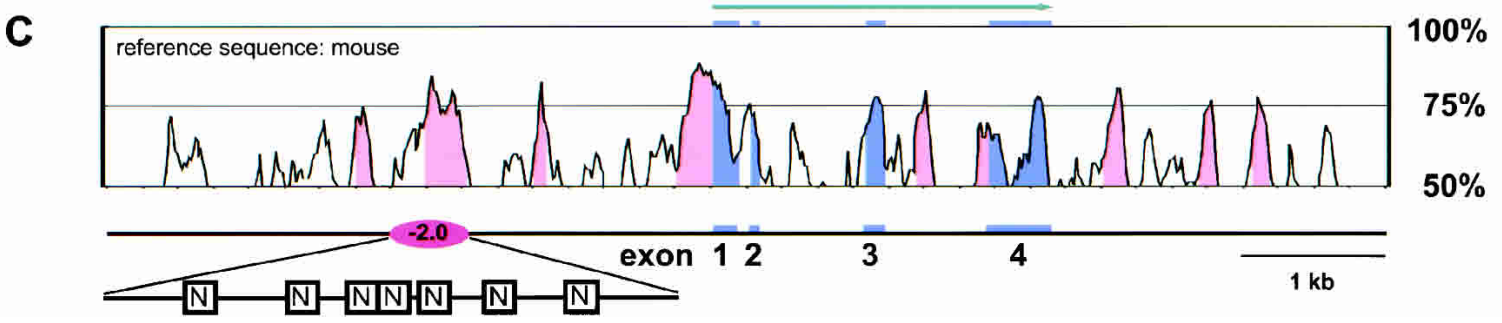

Figure 7. Correlation of conserved noncoding sequences (CNS) with DNase I hypersensitive (DH) sites. Mouse and human sequences containing IL2 and the linked IL3/GM-CSF loci were subjected to VISTA comparison to identify CNS regions, followed by Findpatterns analysis to identify conserved NFAT sites. We considered (A or T)GGAAA to be optimal, but also searched with (A or T)GGAGA and the minimal motif GGAA in order to detect suboptimal NFAT binding sites. In each VISTA graph, the extent of sequence identity is plotted on the $Y$-axis against the indicated reference sequence (human or mouse); exons are shown in blue; CNS, with $>75 \%$ conservation, in pink. Note that the CNS flanking the transcriptional units have higher sequence similarity between human and mouse than do the exons (this is likely to reflect strong evolutionary pressure from pathogens on the cytokine genes). A diagram of predicted, conserved NFAT binding sites in one biologically interesting CNS is given below each graph. (N) NFAT; (A) AP-1. (A) IL-2. The bifurcated CNS immediately upstream of the start of transcription correlates with DH sites II (constitutive) and III (inducible) observed by Siebenlist et al. (1986). The two 5' CNS regions are not hypersensitive under their conditions. The ARRE2 composite NFAT:AP-1 site (Fig. 5) is indicated. (B) IL-3. The indicated CNS corresponds to both the inducible $-4.5 \mathrm{~kb}$ and the constitutive -4.1 $\mathrm{kb}$ DH sites observed by Hawwari et al. (2002); the second and third CNS correlate with the constitutive sites at -1.5 and $-0.1 \mathrm{~kb}$ (promoter). (C) GM-CSF. The second and fourth CNS correlate with the inducible DNase I hypersensitive sites at -2.0 and $-0.1 \mathrm{~kb}$ (promoter) described by Osborne et al. (1995); the first and third CNS are not hypersensitive under their conditions. Accession numbers for the sequences used are NT_007072 (human IL3 and GM-CSF), NT_039520 (murine IL3 and GM-CSF), NT_016354 (human IL2), and NT_039228 (murine IL2).

recognized sites need to be validated by biological experiments.

\section{Redundant versus nonoverlapping functions of individual NFAT proteins}

The different NFAT proteins appear to have relatively redundant functions in cells, as judged by the generally mild phenotypes of mice lacking individual NFAT proteins (for review, see Crabtree and Olson 2002). In three notable exceptions, deletion of NFAT2 results in embryonic lethality because of defects in cardiac valve forma- tion (de la Pompa et al. 1998; Ranger et al. 1998a), the smallest isoform of NFAT2 is selectively unable to promote apoptosis in T cells (Chuvpilo et al. 2002), and deletion of NFAT1 alone substantially reduces cytokine production by mast cells (Tsytsykova and Goldfeld 2000; Solymar et al. 2002). In most cases, however, pronounced functional impairments are not observed unless two or more NFAT proteins are lacking. For instance, deletion of both NFAT1 and NFAT2 is required for effective loss of cytokine production in T cells (Peng et al. 2001); deletion of both NFAT1 and NFAT4 is required to produce a major bias toward Th2 cytokine production in mice 
(Ranger et al. 1998b); deletion of both NFAT3 and NFAT4 is required to produce lethal defects in vascular patterning in the embryo (Graef et al. 2001a); and deletion of three members-NFAT1, NFAT3, and NFAT4is required to observe striking defects in axonal outgrowth in the central and peripheral nervous systems (Graef et al. 2003). The disparate phenotypes of NFATdeficient mice (Crabtree and Olson 2002) may therefore reflect differences in intracellular regulation (see above) and/or different expression levels in different cell types. In fact constitutively active versions of NFAT1 and NFAT2, in which a large fraction of the phosphorylated serines have been mutated to alanine to mimic the dephosphorylated form, have been generated (Macián et al. 2002; Monticelli and Rao 2002; Porter and Clipstone 2002); when expressed at low levels in T cells, under conditions in which the activities of endogenous NFAT proteins are blocked with CsA, the two proteins are similar in their ability to elicit expression of most cytokine genes (Monticelli and Rao 2002).

Despite the apparently interchangeable activities of NFAT proteins in acute assays for gene expression, NFAT2 is reported to have a predominant role in at least two cellular differentiation programs in vivo: differentiation of osteoclasts from monocyte precursors (Takayanagi et al. 2002) and differentiation of Th2 cells from antigen-"naive" $\mathrm{T}$ cells (for review, see Glimcher and Murphy 2000). This could reflect selective regulation of NFAT2 as reported for developing skeletal muscle cells (Abbott et al. 1998). Alternatively, if the precursors contain multiple members of the NFAT family as shown for naive $T$ cells, the bias could stem from the fact that the smallest isoform of NFAT2 is the only NFAT protein subject to positive autoregulation (Chuvpilo et al. 1999; Zhou et al. 2002). Based on precedents in other systems (Davidson 2001), a likely scenario is that the NFAT proteins present in resting naive $T$ cells become activated at the start of the T-cell differentiation program, and upregulate expression of the small isoform of NFAT2. This protein then maintains high levels of its own expression in a positive feedback loop. If, as is likely, high-level expression is essential to maintain the differentiated state, loss of the redundant NFAT proteins present at low levels in the resting precursor cells would have little or no discernible effect on the differentiation program, whereas genetic manipulations that resulted in loss of the short NFAT2 isoform would have a major effect. This distinction may be exacerbated by the fact that, as discussed above, the short NFAT2 isoform has a transactivation domain that differs significantly from those of the other NFAT proteins, and so may assemble into different types of transcriptional complexes in the nucleus.

\section{NFAT-regulated target genes in differentiated T cells}

Study of NFAT function in the immune system has the major advantage that very many NFAT target genes are known. Many such genes were identified by individual analysis of T cells, B cells, NK cells, and mast cells activated through their antigen and Fc receptors (for re- view, see Rao et al. 1997; Kiani et al. 2000; Serfling et al. 2000; Macián et al. 2001). Others were found by analysis of cells lacking one or more members of the NFAT family: For instance, mature $\mathrm{T}$ cells express predominantly two NFAT proteins, NFAT1 and NFAT2, and T cells lacking both proteins produced almost no cytokines upon stimulation (Peng et al. 2001), indicating that NFAT is essential for activating transcription of most T-cell cytokine genes. Yet others have been found by DNA array analyses: For instance, transcriptional profiling of $\mathrm{T}$ cells from control individuals and from patients with a primary defect in store-operated $\mathrm{Ca}^{2+}$ entry revealed that almost as many genes are repressed as are activated by $\mathrm{Ca}^{2+} /$ calcineurin signaling (Feske et al. 2001). It is likely that many of the calcineurin-regulated genes are also NFAT target genes. NFAT could repress gene transcription by recruiting corepressors or by partnering with known transcriptional repressors on DNA; it has been suggested that CDK4 transcription can be repressed by recruiting histone deacetylases to a site just $3^{\prime}$ of the transcription start site of the CDK4 gene (Baksh et al. 2002).

Transcriptional profiling of differentially stimulated $\mathrm{T}$ cells revealed two distinct classes of NFAT target genes, one class controlled by NFAT with AP-1 and the other class by NFAT without AP-1 (Macián et al. 2002). The NFAT:AP-1 complex regulates a very large set of activation-associated genes, classically associated with an ongoing immune response; it is formed through activation of both $\mathrm{Ca}^{2+}$ and PKC/MAP kinase signaling pathways as discussed previously. In contrast, $\mathrm{Ca}^{2+}$ signaling without PKC/MAP kinase signaling activates NFAT but not AP1 , inducing a much smaller set of genes that encode putative negative regulators of the immune response. It is striking that the same transcription factor, NFAT, can impose these two opposing biological programs in the same cells. The genes controlled by NFAT without AP-1 may be regulated through $\kappa \mathrm{B}$-like DNA elements that bind NFAT dimers (see above); or through elements to which NFAT binds cooperatively with partners that are present in resting cells or are activated by $\mathrm{Ca}^{2+}$ signaling.

\section{Involvement of NFAT in chromatin-based processes underlying cell differentiation}

Not only does NFAT regulate gene expression programs in fully differentiated $\mathrm{T}$ cells, but also it plays a critical role in the differentiation process itself (Avni et al. 2002; for review, see Avni and Rao 2000; Ansel et al. 2003). Naive $T$ cells are $T$ cells that have matured in the thymus and emerged into the periphery but have not yet encountered antigen. When these cells are first exposed to antigen, they differentiate into effector $\mathrm{T}$ cells with the ability to transcribe specific subsets of cytokine genes in response to secondary stimulation. Effector Th1 cells transcribe the IFN- $\gamma$ gene but silence the linked $I L-4, I L-5$, and $I L-13$ genes, whereas effector Th2 cells display the converse expression pattern. The process of Th1/Th2 differentiation involves early antigen-induced changes in chromatin structure at all these cytokine 
Hogan et al.

genes; these changes are transient unless maintained by simultaneous stimulation with cytokines (IL-12 and IL-4 for Th1 and Th2 differentiation, respectively). Mechanistically, the first stimulation with antigen and cytokine elicits transient activation of NFAT and STAT transcription factors (STAT4 and STAT6 in response to IL-12 and IL-4 stimulation, respectively). NFAT cooperates functionally with STAT proteins at cytokine regulatory regions, initiating long-range changes in DNase I hypersensitivity and histone modification throughout the locus. At the same time antigen and cytokine stimulation synergize to induce (presumably via NFAT and STAT factors) the expression of lineage-specific transcription factors that maintain the transcriptionally competent status of the cytokine genes. Like NFAT2, the lineagespecific factors (T-bet and GATA 3 in Th1 and Th2 cells, respectively) autoregulate their own expression, thus contributing to maintenance of the differentiated state; upon restimulation with antigen, they cooperate with NFAT to induce rapid, high-level expression of the cytokine genes.

\section{Other biological systems in which NFAT is implicated}

NFAT is expressed in many cell types and contributes to diverse cellular functions (Crabtree and Olson 2002; Horsley and Pavlath 2002; Graef et al. 2003; Hill-Eubanks et al. 2003). As discussed in the previous sections, the cellular context, the source and timing of the $\mathrm{Ca}^{2+}$ / calcineurin signal, the nature of other signals that are activated at the same time, and the flexibility of NFAT in forming transcriptional complexes with different partners, all make important contributions to the final biological output. In this section we discuss three selected systems of cell differentiation in which $\mathrm{Ca}^{2+} /$ calcineurin signaling and NFAT activation have been implicated.
Like Th1/Th2 differentiation, osteoclast differentiation represents a developmental choice in which NFAT drives a common precursor cell toward one of two distinct sibling lineages (macrophages or osteoclasts) by controlling the expression of a specific subset of target genes. In cardiac valve development, NFAT is called upon to make a spatially and temporally precise contribution to a complex morphogenetic program, in which NFAT activation in a very small subset of cells at a very specific time is essential for tissue remodeling. In slowtwitch fiber differentiation in skeletal muscle, NFAT participates in activity-dependent reprogramming of myosin heavy chain (MyHC) gene expression, sensing a $\mathrm{Ca}^{2+}$ signal that reflects a prolonged change in the pattern of contractile activity, and effecting a change in phenotype of a fully differentiated cell.

\section{Osteoclast differentiation}

Osteoclasts are key cellular participants in bone resorption and remodeling. They differentiate from precursors belonging to the monocyte/macrophage lineage under the influence of signals from osteoblasts or bone marrow stromal cells (Chambers 2000; Teitelbaum 2000). Secreted M-CSF and RANKL presented on the surface of osteoblasts or stromal cells are the essential signals in vivo, with other extracellular signaling molecules and substrate adhesion also playing a role. The transcription factors c-Fos and NFKB have been recognized as essential for osteoclast differentiation based on the osteopetrotic phenotype of c-Fos- and NFкB-deficient mice (Grigoriadis et al. 1994; Franzoso et al. 1997). Osteoclast differentiation is a process occurring over several days (Fig. 8), with sequential expression of markers and, usually, fusion into multinucleated cells. Fully mature osteoclastic cells are marked by the expression of the calcitonin re-

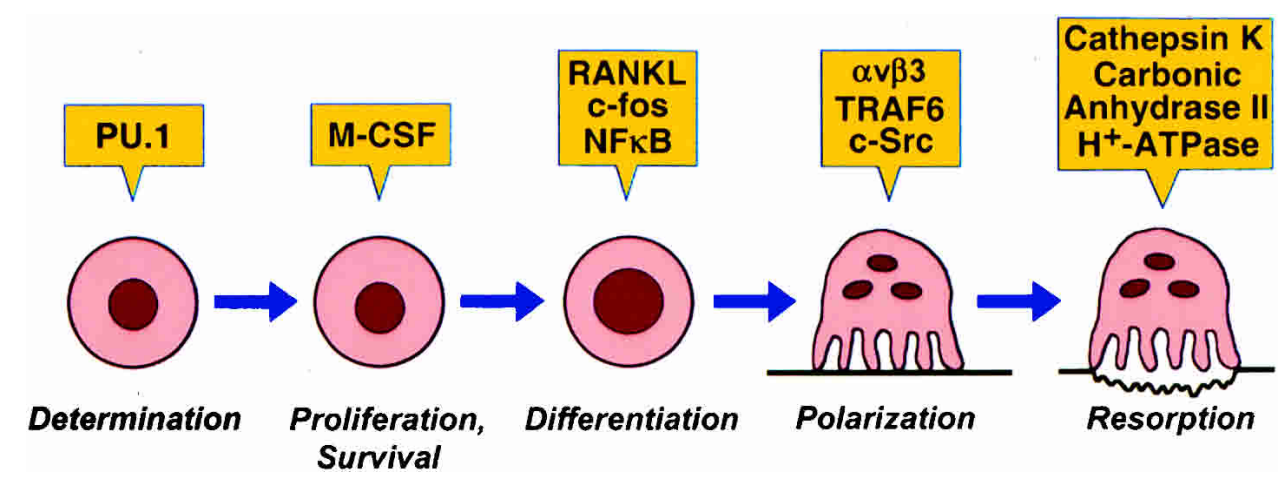

Figure 8. Osteoclastogenesis. Osteoclast differentiation is a multistep process occurring over several days. Its stages have been defined genetically by the point at which osteoclast development is arrested in animals when the function of specific genes is absent (yellow boxes). The early stages of commitment to the monocyte/macrophage/osteoclast lineages and the survival and proliferation of precursor cells require the transcription factor PU.1 and the signal provided by M-CSF. Differentiation requires the further signal supplied by RANKL, and signaling via the transcription factors c-Fos and NFkB. Recent work indicates that signaling via NFAT is also essential. Cellular polarization and productive attachment to the bone substrate, a prerequisite for bone resorption, depend on $\alpha_{v} \beta_{3}$ integrin and the intracellular signaling proteins TRAF6 and c-Src. Bone resorption by fully differentiated osteoclasts is carried out by effector proteins including cathepsin $\mathrm{K}$, carbonic anhydrase II, and a specific $\mathrm{H}^{+}$ATPase. Figure reprinted with permission from Teitelbaum (2000). (C) 2000 American Association for the Advancement of Science. 


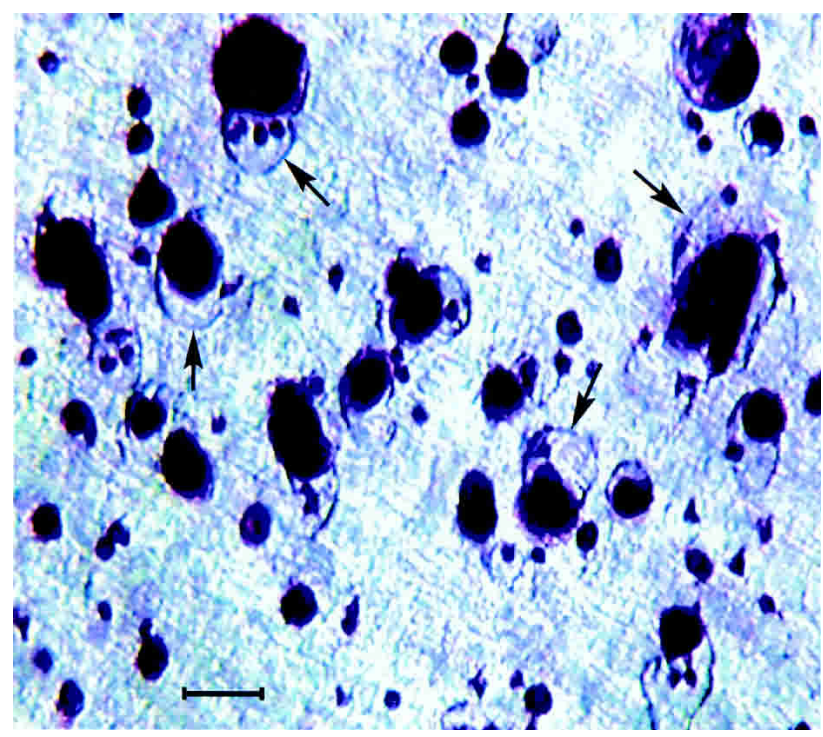

Figure 9. Bone marrow cells can be induced to differentiate into osteoclasts in vitro. Mouse bone marrow macrophages were treated with M-CSF and RANKL in vitro for $6 \mathrm{~d}$. The cells pictured are attached to whale dentin, an alternative target for resorption by osteoclasts. Full expression of the osteoclast differentiation program in these cells is demonstrated by their strong tartrate-resistant acid phosphatase staining (purple) and by the resorption pits (arrows) visible adjacent to some of the cells. Bar, $50 \mu \mathrm{m}$. Micrograph credited to Deborah Novack, reprinted with permission from Teitelbaum (2000). (c) 2000 American Association for the Advancement of Science.

ceptor (Hattersley and Chambers 1989) and the ability to resorb bone.

Various experimental models of osteoclast differentiation have been developed. The combination of M-CSF and soluble RANKL will support differentiation of osteoclasts from a mixed population of bone marrow cells or spleen cells (Fig. 9; Lacey et al. 1998; Yasuda et al. 1998), and inclusion of TGF $\beta$ increases the yield of differentiated cells (Chambers 2000). The cellular complexity of the model is reduced in studies using the RAW264.7 monocyte/macrophage cell line, which undergoes differentiation when stimulated with soluble RANKL alone or with RANKL together with additional signals (Hsu et al. 1999; Meiyanto et al. 2001; Ishida et al. 2002; Shui et al. 2002). With some protocols, RAW264.7 cells progress to multinucleated osteoclast-like cells that express calcitonin receptor (Shui et al. 2002) and are able to resorb bone in vitro (Hsu et al. 1999; Meiyanto et al. 2001; Shui et al. 2002).

Both calcineurin signaling and NFAT have been implicated in the differentiation of osteoclasts. In an early report using limb bones cultured from fetal rats, CsA did not initially alter bone resorption, but decreased bone resorption after several days in culture, a finding attributed to its inhibition of osteoclast formation (Orcel et al. 1991). A more compelling connection between calcineurin and osteoclast differentiation has been made in a bone marrow culture model, in which either CsA or FK506 caused a concentration-dependent inhibition of differentiation of tartrate-resistant acid phosphatase (TRAP)-positive multinucleated cells (Takayanagi et al. 2002). Similarly, in the RAW264.7 cell model of osteoclastogenesis, CsA blocked RANKL-induced formation of multinucleated cells (Ishida et al. 2002), and either CsA or FK506 largely inhibited formation of multinucleated cells and up-regulation of calcitonin receptor mRNA by the combination of M-CSF, RANKL, and TGFß (Shui et al. 2002). Two separate lines of evidence implicate NFAT2 in the process. First, NFAT2 ${ }^{-/-}$ES cells fail to differentiate into osteoclasts under conditions in which wild-type cells differentiate (Takayanagi et al. 2002). Second, in RAW264.7 cells, reduction of NFAT2 protein levels by introduction of an antisense NFAT2 construct mimicked the inhibitory effect of CsA on formation of multinucleated cells (Ishida et al. 2002). The latter conclusion is provisional, because unexpectedly the effect did not require induction of the antisense mRNA with doxycycline, and because no control antisense constructs were tested.

Both the experiments with bone marrow cells (Takayanagi et al. 2002) and those with RAW264.7 cells (Ishida et al. 2002) have provided evidence of a two-stage differentiation process, in which first NFAT2 expression is switched from a relatively low to a relatively high level by inducible transcription factors including c-Fos and $\mathrm{NF} \kappa \mathrm{B}$, and then NFAT2 cooperates with some of the same proteins to activate transcription from promoters of genes characteristic of terminal differentiation. Depending on the experimental model, there are differences in detail at the first stage. In bone marrow osteoclasts, FK506 blocked NFAT2 mRNA and protein induction, and overexpression of NFAT2 forced expression of the endogenous NFAT2 gene. Moreover, c-Fos was necessary for NFAT2 expression. These findings are circumstantial evidence that the calcineurin-NFAT pathway participates in NFAT2 induction through composite NFATAP1 sites in the NFAT2 promoter, a mechanism that has been documented previously in $\mathrm{T}$ cells (Chuvpilo et al. 2002; Zhou et al. 2002). In RAW264.7 cells, in contrast, CsA did not block NFAT2 protein induction or TRAP expression, even though it prevented progression to multinucleated cells (Ishida et al. 2002). The difference is not a major discrepancy, but rather suggests that it is possible to bypass the requirement for NFAT when certain other transcription factors are present in sufficient amounts. It is clear from other evidence that the signaling context in RAW264.7 cells diverges from that in the bone marrow osteoclast precursors, because RAW264.7 cells need only RANKL stimulation to trigger differentiation.

Points that have not been clarified for differentiating bone marrow cells are the source of the $\mathrm{Ca}^{2+}$ signal that initiates up-regulation of the NFAT2 gene and whether NFAT2 itself or another NFAT-family protein transmits the $\mathrm{Ca}^{2+}$ signal at the earliest times. NFAT4 mRNA has been detected by DNA microarray analysis in a bone marrow cell population that contains precursors of osteoclasts (M. Sǔsă, pers. comm.), and NFAT1 protein and NFAT4 mRNA have been documented in RAW264.7 
cells (Wang et al. 1995; Ishida et al. 2002). It can be presumed that, beyond the earliest times of induction, NFAT2 expression becomes self-reinforcing as the protein accumulates and is activated.

In the second stage of differentiation, when NFAT cooperates with other factors to control a collection of differentiation genes, the basis for its transcriptional signaling is clear. NFAT protein levels are high. Newly accumulated NFAT2 protein is at first mainly cytoplasmic, both in differentiating bone marrow cells and in RAW264.7 cells (Ishida et al. 2002; Takayanagi et al. 2002). As part of the differentiation process, RANKL leads to cytoplasmic $\mathrm{Ca}^{2+}$ oscillations after $\sim 24 \mathrm{~h}$ (Takayanagi et al. 2002), and NFAT2 becomes mainly nuclear by $72 \mathrm{~h}$ in differentiating bone marrow osteoclasts, and by day 2 of stimulation with RANKL in RAW264.7 cells (Ishida et al. 2002; Takayanagi et al. 2002).

Target genes for NFAT may include many of the definitive differentiation markers of osteoclasts. Sequences typical of composite NFAT-AP1 sites can be recognized in the promoters of several osteoclast genes, including the genes encoding TRAP and calcitonin receptor (Anusaksathien et al. 2001; J. Nardone, unpubl.). NFAT2 and c-Fos act synergistically at the TRAP promoter, and this cooperation requires NFAT2 residues that have been shown to stabilize the NFAT-AP1 interaction (Takayanagi et al. 2002), consistent with NFAT-AP1 cooperation at composite sites in the TRAP promoter. Overexpression of NFAT2 in osteoclast precursor cells causes differentiation in the absence of RANKL (Takayanagi et al. 2002). A physical interpretation, to the extent that composite NFAT-AP1 sites are used, is that a high level of NFAT shifts the equilibrium for complex formation on DNA so that the lower levels of AP1 proteins present without RANKL stimulation are sufficient. It is plausible that a similar shift occurs in the requirement for

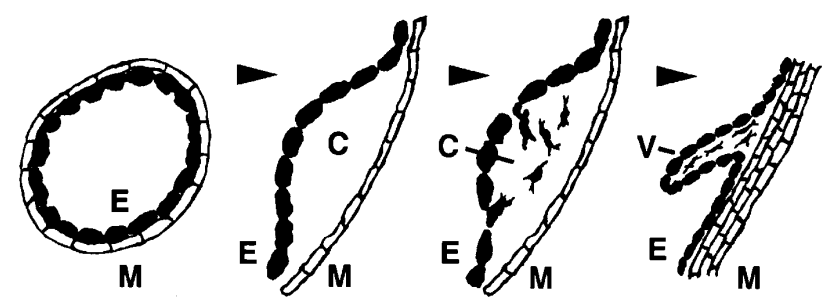

Figure 10. Schematic view of cardiac valve formation. The primitive heart tube consists of two cellular layers, an outer layer of developing myocardium and an inner layer of developing endocardium. Initially, the cardiac cushions form as locally thickened extracellular matrix between the myocardial and endocardial cell layers. Later some cells of the endocardial layer detach from their neighbors, undergo an endothelial $\rightarrow$ mesenchymal transition, and migrate into the underlying cardiac cushion. This migration is followed by secretion of additional components of extracellular matrix, cell proliferation, further differentiation, and remodeling of the valve as a whole into its definitive morphology. In the schematic diagram, labels indicate the endothelial (E) and myocardial (M) layers for orientation, the acellular cardiac cushion primordium or the cardiac cushion $(\mathrm{C})$, and the fully formed valve $(\mathrm{V})$.
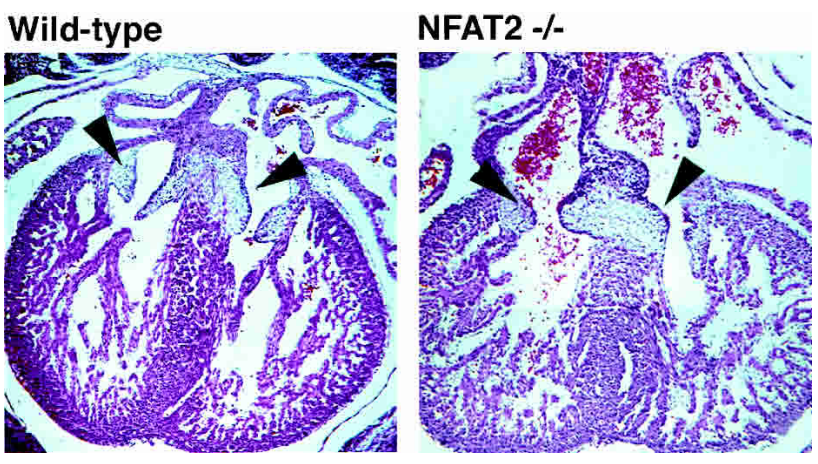

Figure 11. Development of the cardiac valves is abnormal in NFAT2-null mouse embryos. Micrographs of sections from mouse heart at E13.5. At this stage in wild-type embryos, the atrioventricular valves (arrows) have formed and have been extensively remodeled. In NFAT2-null mice, the atrioventricular valves (arrows) are poorly developed. Figure reprinted with permission from de la Pompa et al. (1998). (C) 1998 Nature Publishing Group.

other cooperating transcription factors when NFAT2 is overexpressed.

The models of osteoclast differentiation are attractive experimental preparations for studying how NFAT signaling is integrated with other inputs in a progressive process of differentiation. The experiments so far have uncovered a diverse set of potential target genes including previously characterized markers of osteoclast differentiation and the genes shown by microarray analysis to be induced in differentiating osteoclasts (Cappellen et al. 2002; Takayanagi et al. 2002) and in RAW264.7 cells (Ishida et al. 2002). These well-defined in vitro models will permit increasingly fine dissection of the role of NFAT in differentiation of osteoclasts from their precursor cells, in terms of which genes are controlled, the timing of their induction, the promoter sites where NFAT binds, and the partner proteins that cooperate in gene induction.

\section{Cardiac valve development}

Vertebrate heart development is a choreographed progression-intricately patterned in time and space-from specification of cardiogenic mesoderm to an anatomically organized and functioning heart (Fishman and Chien 1997; Sucov 1998; Bruneau 2002; McFadden and Olson 2002). One crucial element of cardiogenesis is the formation of valves between the developing atrial and ventricular chambers and in the outflow tract (Eisenberg and Markwald 1995). In outline, this process requires specification of the locations at which the valve primordia will form; the initial elaboration of an acellular matrix at these sites; the population of this matrix by cells that originate in the early endothelium; and subsequent cell proliferation, production of matrix materials, and remodeling (Fig. 10).

Gene targeting has implicated NFAT2 in this developmental process. Mice homozygous for two different 
single-exon deletions in the NFAT2 gene display defects in cardiac valve and septum formation (Fig. 11; de la Pompa et al. 1998; Ranger et al. 1998a). Consistent with the observed developmental deficits, NFAT2 mRNA and protein are present in murine cardiac endothelium throughout the period of cardiac morphogenesis from a simple tube to a four-chambered heart (de la Pompa et al. 1998; Ranger et al. 1998a; Kim et al. 2001). NFAT2 is not detected in the two other classes of cells directly involved in valve development, myocardial cells and cardiac cushion mesenchymal cells.

NFAT is activated in the cardiac endothelium of wildtype embryos. The NFAT2 protein in endocardial cells lining the cardiac cushions is mostly localized to the cell nuclei in the relevant period from embryonic day 8.5 (E8.5) to E12.5, and its nuclear localization is reversed by a high concentration of CsA or FK506 applied to the whole embryo (de la Pompa et al. 1998; Ranger et al. 1998a). These observations are consistent with an ongoing local signal, from myocardium or from endocardium itself, that acts intracellularly through the $\mathrm{Ca}^{2+} /$ calcineurin pathway to activate NFAT. Fluid shear forces are also likely to trigger or modulate transcription locally in the embryonic heart (Hove et al. 2003), but their connection to activation of NFAT has not been investigated. A less conventional proposal, based on the reduced nuclear localization of NFAT2 in atrioventricular canal endothelium of connexin-45-null mouse embryos at E9.5, is that a signal to activate the $\mathrm{Ca}^{2+}$ /calcineurin pathway propagates laterally between endocardial cells via gap junctions (Kumai et al. 2000). However, connexin-45 is predominantly expressed in myocardium rather than in endothelium (Alcoléa et al. 1999), and already at E9-E9.5, the myocardium of connexin-45-null mouse embryos shows impaired conduction and contractile activity in the atrioventricular canal (Kumai et al. 2000). Thus the observations in connexin-45-null embryos might equally be explained in more conventional terms, either by reduced signaling from myocardium or by reduced shear stresses.

A possible local signal for NFAT activation is VEGF, which triggers nuclear import of NFAT2 in pulmonary valve endothelial cells cultured from postnatal human heart (Johnson et al. 2003), just as VEGF triggers activation of NFAT1 in vascular endothelial cells (Armesilla et al. 1999; Hernández et al. 2001). VEGF and its receptor VEGF-R2/Flk-1 are present in the heart rudiment, and it is known that increased expression of VEGF at E10 terminates the endothelial $\rightarrow$ mesenchymal transformation in the valve primordia and possibly promotes expansion and differentiation of the endothelial cell layer (Dor et al. 2001, 2003). Given that NFAT protein is nuclear as early as E8.5, if, in fact, VEGF is the principal trigger for NFAT activation, even the low levels of VEGF present before E10 have a direct role in cardiac valve formation.

It has not been resolved whether the crucial requirement for NFAT2 in cardiac valve development is for transcription of a gene (or genes) during remodeling of the cardiac cushions into the definitive valve morphol- ogy, or for transcription in early endothelium that sets the cellular context for later developmental decisions when these cells complete differentiation as endothelium or leave the endothelium and become cardiac cushion mesenchymal cells. The prominent nuclear localization of NFAT2 both early in the endothelium of the heart tube and later in endothelium overlying the cardiac cushions is consistent with either scenario. It also remains to be determined whether the abnormalities in mice deficient in NFAT2 are caused by an altered level and timing of expression of endothelial genes that are common to cardiac and vascular endothelium, or result from failure to read out genes that are specific to cardiac endothelium. The preferential expression of NFAT2 and GATA5 in cardiac endothelial cells hints at the latter possibility.

Insight into the transcriptional targets downstream of NFAT2 in later stages of cardiac endothelial development has come from experiments with the TC13 cell line (al Moustafa and Chalifour 1993), which serves as a model of differentiation of cardiac mesoderm into endocardium. In these cells, NFAT2 and GATA5 synergistically activate a luciferase reporter linked to the endothelin-1 (EDN1) promoter (Nemer and Nemer 2002). Reduced expression of endothelin-1 would not by itself explain the defects in NFAT2-null mice, because the cardiac phenotype of EDN1-null mice has rather low penetrance and is basically restricted to the outflow tract (Kurihara et al. 1995). However, GATA5 is a key transcription factor in expression of the endothelial/endocardial repertoire in TC13 cells (Nemer and Nemer 2002), and is likely to play a similar role in the embryo through its expression in precardiac mesoderm and its progressive restriction, within the heart, to endothelium during early cardiogenesis (Morrisey et al. 1997). In establishing that NFAT2 can cooperate with GATA5, the example of the EDN1 promoter highlights the possibility that endocardial gene promoters will become a case study for functional and biochemical interactions of NFAT- and GATA-family proteins.

Physiological control of myosin heavy chain I (MyHC I) expression

Mammalian skeletal muscles are a mosaic of muscle fibers that differ in their complement of myofibrillar proteins and of metabolic enzymes, and therefore in their contractile properties (Fig. 12). The contractile properties of individual muscle fibers correlate with the $\mathrm{MyHC}$ isoform expressed. Thus, a useful classification divides muscle fibers into four principal types: slow-twitch fibers that express MyHC I, and three subtypes of fasttwitch fibers that express MyHC IIa, IId, or IIb, respectively (Pette and Staron 2000). Prolonged changes in the contractile activity of a differentiated muscle fiber can alter the expression of $\mathrm{MyHC}$ and other genes, and thus can cause a transition of an existing muscle fiber from one class into another. Completion of such a transition requires weeks, owing to the slow turnover of myofibrillar proteins. 


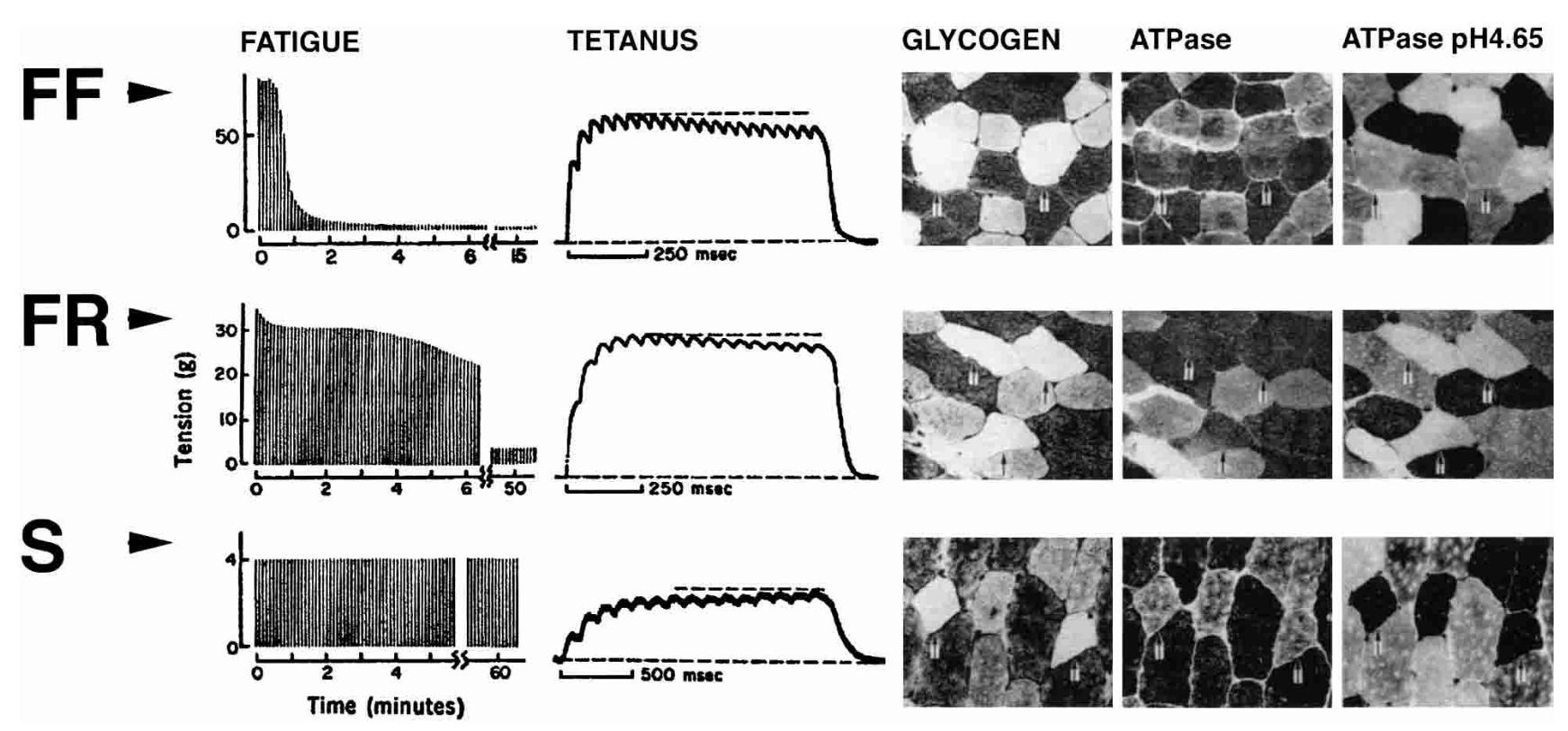

Figure 12. Muscle fiber contractile properties correlate with the isoform of myosin present. This point was first established by observing the contractile properties of individual motor units, the subset of muscle fibers that contract when a single motor nerve axon is stimulated. In the experiment illustrated, three classes of mechanical response were observed in cat gastrocnemius, and designated FF, FR, and S. (In the classification adopted in this review, FF motor units consist of type IIb or IId fibers, FR units of type IIa fibers, and S units of type I fibers.) The responses are most reliably classified by the rate of decline in peak tension during repeated trains of stimulation (FATIGUE) and by the presence or absence of a slight "sag" in the response to a single train of stimuli (TETANUS). After the contractile properties were determined, muscle fibers belonging to the motor unit were marked by prolonged stimulation to deplete their stores of glycogen, and serial cross-sections were made from the muscle. Sets of cross-sections from the same muscles whose mechanical responses are depicted at the left show the fibers marked by depletion of glycogen (arrows) and the staining for myofibrillar ATPase under different conditions. Individual myosin isoforms have differing intrinsic ATPase activity and differing sensitivity to preincubation at $\mathrm{pH} 4.65$, and this feature is apparent in the mosaic pattern of ATPase staining. However, all the muscle fibers innervated by a single axon shared a common history of activity prior to the experiment, and have similar myofibrillar ATPase staining. This experiment was not designed to answer whether individual muscle fibers express a single isoform of MyHC or a mixture of isoforms. However, more recent studies of dissected single muscle fibers have documented the tight correlation between muscle contractile properties, specifically speed of contraction, and the specific myosin isoform expressed (for review, see Pette and Staron 2000). Figure modified with permission from Burke et al. (1971). (C) 1971 American Association for the Advancement of Science.

Calcineurin, NFAT, and induction of MyHC I gene expression: Calcineurin is clearly implicated in the transition in which fully differentiated fast-twitch muscle fibers are induced by chronic activity to express slowtwitch MyHC I. In one experimental model, myotubes from newborn rabbit hindlimb muscles were grown in culture on gelatin bead microcarriers, which provide firm anchorage for the myotubes and prevent the detachment of mature contracting myotubes that usually occurs in culture (Kubis et al. 1997). Over a period of weeks, the cultures matured to contain a mixture of the fast-twitch MyHC isoforms IIa, IId, and IIb, and negligible levels of the slow-twitch MyHC I (Kubis et al. 1997; Meißner et al. 2000, 2001; Kubis et al. 2002). Electrical stimulation in a pattern characteristic of the activity of slow-twitch muscle altered the course of maturation, resulting in elevated expression of MyHC I mRNA and protein (Meißner et al. 2001; Kubis et al. 2002). The $\mathrm{Ca}^{2+}$ ionophore A23187 mimicked this effect of stimulation (Kubis et al. 1997; Meißner et al. 2000, 2001), and CsA prevented the up-regulation of MyHC I mRNA and protein in both cases (Meißner et al. 2001), thus implicating a $\mathrm{Ca}^{2+} /$ calcineurin pathway in the process. A second model examined isolated individual skeletal muscle fibers from mouse flexor digitorum brevis (Liu and Schneider 1998). This muscle is composed mainly of fast-twitch fibers, and MyHC I expression is not detectable in the majority of fibers by single-fiber reverse transcription-PCR (RT-PCR; Liu and Schneider 1998). When the isolated muscle fibers were stimulated in a pattern characteristic of slow-twitch muscle, MyHC I mRNA became detectable in nearly all the individual fibers within $6 \mathrm{~d}$ (Liu and Schneider 1998). The up-regulation of MyHC I mRNA in these experiments in vitro directly parallels that observed upon comparable electrical stimulation of fast-twitch muscle in vivo (Kirschbaum et al. 1990; Brownson et al. 1992; Windisch et al. 1998). Both in intact muscle stimulated ex vivo and in the rabbit myotubes, an increase in MyHC I mRNA is detected as early as $24 \mathrm{~h}$ after the onset of stimulation (BartonDavis et al. 1996; Kubis et al. 2002, 2003).

Several other experimental protocols have implicated calcineurin in activity-dependent replacement of MyHC II isoforms by MyHC I in vivo (Dunn et al. 1999; Serrano 

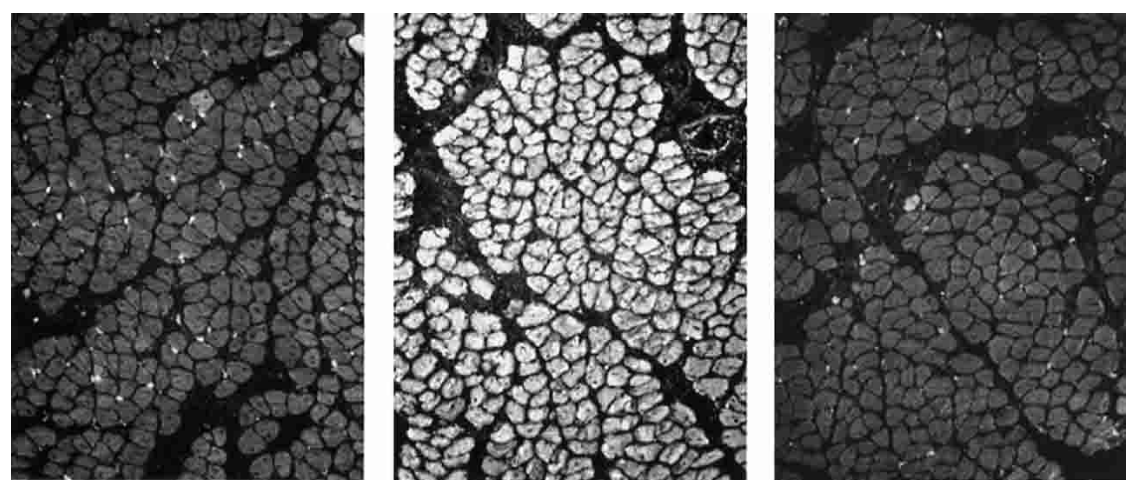

Figure 13. CsA prevents expression of MyHC I in response to activity. Rat soleus muscles were denervated, damaged with bupivacaine, and allowed to regenerate. Cross-sections were taken after regeneration from a muscle that had not been stimulated (left), a muscle that had been stimulated electrically in a firing pattern resembling slow-twitch muscle activity (center), and a muscle that had been electrically stimulated and treated with CsA (right). Staining with an antibody to MyHC I demonstrated that MyHC I protein was present in the vast majority of fibers in the stimulated muscle, but not in fibers of the unstimulated muscle, and that the appearance of MyHC I was prevented by CsA. Figure reprinted with permission from Serrano et al. (2001). (c) 2001 American Association for the Advancement of Science.

et al. 2001; Irintchev et al. 2002; Pallafacchina et al. 2002; for review, see Schiaffino and Serrano 2002). For instance, CsA, FK506, or overexpression of a fragment of the calcineurin inhibitor Cain/Cabin1 blocks the upregulation of $\mathrm{MyHC}$ I elicited in regenerating rat or mouse soleus muscle by physiological signaling from its nerve (Serrano et al. 2001; Irintchev et al. 2002; Pallafacchina et al. 2002). CsA similarly blocks the up-regulation triggered in denervated regenerating soleus by electrical stimulation (Fig. 13; Serrano et al. 2001). In these protocols, muscle satellite cells recapitulate the developmental progression myoblast $\rightarrow$ myotube $\rightarrow$ muscle fiber and the sequential expression of myosin isoforms that occurs during soleus development, and the signaling pathways and promoter elements called into play are likely to be more complex than in the simple case of electrical stimulation of fully differentiated fast-twitch muscle fibers. CsA blocks the increase in MyHC I mRNA and MyHC I-positive fibers brought about by experimentally induced overload of mouse plantaris in vivo (Dunn et al. 1999). This experimental model also triggers additional signaling pathways, because it leads to a prominent compensatory hypertrophy that initially increases the expression of several myosin isoforms. Finally, calcineurin may contribute to the maintenance of MyHC I expression in slow-twitch muscle fibers in vivo, because chronic CsA treatment results in the partial replacement of MyHC I protein by fast-twitch myosin isoforms in the soleus muscle of mice and rats (Chin et al. 1998; Bigard et al. 2000; Irintchev et al. 2002). Although the in vivo models differ in detail from the in vitro models described above, collectively these findings reinforce the message that calcineurin conveys a signal for expression of MyHC I.

The evidence that NFAT is a transcriptional effector for MyHC I gene expression is more circumstantial. NFAT mRNAs and proteins are present in skeletal muscle, including the rabbit myotubes grown on gelatin beads (Hoey et al. 1995; Abbott et al. 1998; Dunn et al. 2000; Swoap et al. 2000; Meißner et al. 2001; Kubis et al. 2002). NFAT2, or NFAT2-GFP expressed from an adenovirus vector, is activated and imported into the nucleus when the myotubes or muscle fibers are electrically stimulated, and this response is prevented by CsA /Y. Liu et al. 2001; Kubis et al. 2002, 2003). Nuclear import is observed in response to specific patterns of stimulation that produce MyHC I induction, but not in response to a pattern that fails to induce MyHC I (Kubis et al. 2002). Thus, empirically, NFAT is a suitable transcriptional effector to relate muscle activity to MyHC I gene expression, either directly by its binding to the MyHC I promoter or indirectly through regulating genes that control MyHC I induction.

NFAT activation by muscle activity: How does intracellular $\mathrm{Ca}^{2+}$ signaling in skeletal muscle fibers activate NFAT? Contracting skeletal muscle cells generate spikes in cytoplasmic $\mathrm{Ca}^{2+}$ concentration that are exceedingly brief and frequent compared with $\mathrm{Ca}^{2+}$ oscillations in $\mathrm{T}$ cells. The conventional interpretation has been that the brief spikes control contraction, whereas a sustained elevation of baseline $\mathrm{Ca}^{2+}$ controls transcriptional activation. This interpretation may be an oversimplification. Clearly, NFAT in the experimental models can respond to elevated basal $\mathrm{Ca}^{2+}$, and $\mathrm{MyHC}$ I mRNA can be induced, as shown in experiments using $\mathrm{Ca}^{2+}$ ionophores (Kubis et al. 1997; Meißner et al. 2000, 2001; Y. Liu et al. 2001). There is also evidence that basal $\mathrm{Ca}^{2+}$ in fully differentiated slow-twitch fibers is modestly higher than that in fast-twitch fibers (Carroll et al. 1997), a situation that could contribute to the maintenance of MyHC I gene expression in slow-twitch fibers. However, stimulation that initiated the switch to MyHC I expression in the experimental models in vitro produced no change in the fast $\mathrm{Ca}^{2+}$ transients and no change in basal $\mathrm{Ca}^{2+}$ (Liu et al. 1999; Kubis et al. 2003). Thus, although continuous electrical stimulation leads under some conditions to moderate increases in basal $\mathrm{Ca}^{2+}$ (Sreter et al. 1987; Carroll et al. 1999), elevated basal $\mathrm{Ca}^{2+}$ is not an obligatory part of the calcineurin-MyHC I pathway nor of NFAT activation. Rather, NFAT is responding either to the pattern of rapid $\mathrm{Ca}^{2+}$ transients or to highly localized changes in $\mathrm{Ca}^{2+}$ concentration that are not detected as globally elevated basal $\mathrm{Ca}^{2+}$. In either case, the mode of activation differs from the classical mode of NFAT activation by a simple sustained elevation of cytoplas$\operatorname{mic} \mathrm{Ca}^{2+}$.

Once NFAT is activated, moreover, it shows a novel ability to deliver a signal to the nucleus that averages 
muscle activity over lengthy periods, including periods when activity is interrupted by intervals of rest. In both experimental models there was a progressive accumulation of nuclear NFAT2 during ongoing intermittent stimulation, and only a slow or very slow exit of NFAT2 from the nucleus during the intervals between periods of stimulation (Y. Liu et al. 2001; Kubis et al. 2002, 2003). Strikingly, in rabbit myotubes after $24 \mathrm{~h}$ of intermittent stimulation, NFAT remained fully nuclear in the majority of cells even 30 min after stimulation ceased (Kubis et al. 2003), and in the isolated individual muscle fibers, export of NFAT2 was incomplete even $2 \mathrm{~h}$ after stimulation ended (Y. Liu et al. 2001). The slow nuclear accumulation and slow export of NFAT2 in skeletal muscle stand in contrast to the rapid import and export of NFAT proteins in $\mathrm{T}$ cells. The underlying mechanism is not known: Calcineurin signaling could be prolonged in the nucleus of fibers subjected to chronic low-frequency stimulation, the capacity for rephosphorylation of NFAT could be limited by low levels or by inhibition of the relevant kinases, or export of NFAT from the nucleus could lag behind rephosphorylation.

The effective confinement of intracellular $\mathrm{Ca}^{2+}$ signaling to restricted spatial domains is increasingly recognized (Zaccolo et al. 2002). Skeletal muscle fibers, in particular, with their stereotyped ultrastructural organization, offer vast opportunities for spatial compartmentalization of signaling, and it is conceivable that compartmentalization shapes the response of NFAT to muscle activity. In the experiments on isolated single muscle fibers, NFAT2-GFP was present at the Z-disks (Y. Liu et al. 2001). Calsarcin-family proteins mediate binding of a proportion of skeletal muscle calcineurin to the Z-disks (Frey et al. 2000; Frey and Olson 2002), placing both calcineurin and NFAT2-GFP near the sites of intracellular $\mathrm{Ca}^{2+}$ release-junctional triads-which flank the Z-disks. On the other hand, overexpressed NFAT2-GFP was not detectably depleted from these sites by physiological stimulation that produced maximal nuclear import (Y. Liu et al. 2001), whereas endogenous NFAT2 in differentiated myotubes could be essentially quantitatively recruited to the nucleus (Kubis et al. 2003). Possibly the Z-line sites are not the source of NFAT2 that is recruited to the nucleus; alternatively, it may be that these sites are the source under physiological conditions, but that overexpression of NFAT2-GFP provides much higher levels of protein than can be processed by the signaling and nuclear import machinery. It will be important to know whether the observed localization of NFAT2-GFP reflects the localization of endogenous NFAT2 or other endogenous NFAT isoforms in muscle cells, and, if so, whether this spatial distribution is mandatory for efficient NFAT activation.

Promoter elements controlling MyHC I expression: The key steps in activity-dependent induction of $\mathrm{MyHC}$ I in fast-twitch fibers have not been delineated, but it is likely that long-range changes in chromatin structure are involved. The MyHC I gene (termed the $\beta$-MyHC gene in the cardiac literature) is at a locus directly adjacent to the cardiac $\alpha-\mathrm{MyHC}$ gene. Only MyHC I is normally expressed in skeletal muscle of adult mammals. Both in vivo and in vitro, however, the transition from fasttwitch to slow-twitch myosin in skeletal muscle is accompanied by the transient expression of cardiac $\alpha$-MyHC (Peuker et al. 1995, 1999; Kubis et al. 1997), suggesting changes in chromatin structure throughout the region containing the linked genes. Conversely, $\beta$-MyHC (MyHC I) is expressed in developing hamster cardiac muscle and is down-regulated in the heart shortly after birth, and corresponding alterations in chromatin accessibility are detectable in prominent DNase I hypersensitive sites $2.3 \mathrm{~kb}$ upstream of the transcription start site and in the proximal promoter region (Huang et al. 1997; Huang and Liew 1998). Initial expression of genes in developmental programs is often controlled by signaling inputs addressed to one promoter module, whereas continuing stable expression is locked in by transferring control to another module with overlapping but not identical inputs (Davidson 2001). To determine whether there are dedicated promoter elements that initiate the fast-twitch to slow-twitch transition in skeletal muscle, it would be useful to map DNAse I hypersensitive sites in the entire locus in fully differentiated fasttwitch and slow-twitch skeletal muscle, as well as in fast-twitch skeletal muscle during the early stages of the MyHC transition.

Maintenance of MyHC I expression in differentiated slow-twitch muscle fibers involves a proximal $\sim 600$-bp promoter element that has been shown to confer expression in slow-twitch skeletal muscle of transgenic animals (Rindt et al. 1993) and additional regulatory regions further upstream of the transcription start site (Rindt et al. 1993; Giger et al. 2000). The requirement for upstream elements is displayed vividly in the higher expression level of a reporter transgene driven by an $\sim 5.6-$ $\mathrm{kb}$ fragment of the MyHC I promoter, compared with the level driven by the 600-bp promoter fragment (Rindt et al. 1993). Although the 5.6-kb promoter fragment gave well-regulated expression of its reporter transgene in mouse soleus (Rindt et al. 1993; Knotts et al. 1996), two of four transgenic lines also showed unanticipated strong expression in mouse masseter (Rindt et al. 1993), a muscle that has no slow-twitch fibers, indicating that even more distal regions containing additional transcriptional control elements remain to be identified. Comparative sequence analysis, discussed in a previous section, shows that there are conserved untranslated sequences scattered to at least $12.5 \mathrm{~kb}$ upstream of the transcription start site of the MyHC I gene (J. Nardone, unpubl.). These observations call for a renewed analysis of which elements of the MyHC I promoter confer expression in slow-twitch muscle fibers in vivo.

Even though information on the cis-acting elements linking muscle activity to MyHC I expression is incomplete, it is useful to consider briefly how NFAT signals could converge with other signals to control the expression of muscle-specific genes. Cellular identity as skeletal muscle is likely to be registered at the gene promoter by muscle-specific transcription factors such as MyoDfamily proteins. The fact that MyHC expression is sen- 
sitive to diverse inputs, including pattern of activity, mechanical loading, hormonal signals, and developmental signals, implies that there are many relevant inducible pathways, but among them two call for special comment. MEF2 proteins are prominent in skeletal muscle and represent a second pathway from calcineurin to DNA (Wu et al. 2000; McKinsey et al. 2002). MEF2 is active in both type I slow-twitch fibers and type IIa fasttwitch fibers, and is downstream of calcineurin in a signaling pathway that controls the transition from type IIb and IId fast-twitch fibers to type IIa fast-twitch fibers in response to muscle activity (Wu et al. 2000, 2001; Allen and Leinwand 2002). In principle, MEF2 could bind in conjunction with NFAT at some promoters (Chin et al. 1998) and convey its signal independently at other promoters. There is also the familiar possibility that AP1 could cooperate with NFAT at the MyHC I promoter as it does at cytokine gene promoters. Here the evidence is circumstantial: First, overexpression of an activated Ras protein, acting via the Ras-MAP kinase pathway, caused expression of MyHC I in denervated regenerating soleus (Murgia et al. 2000); second, overexpression of a dominant-negative form of Ras prevented induction of $\mathrm{MyHC}$ I by reinnervation (Murgia et al. 2000), proving the place of Ras in normal physiological signaling; third, AP1 proteins are downstream effectors of the Ras-MAP kinase pathway; and finally, plausible composite NFAT-AP1 sites are present in the proximal promoter region of the MyHC I gene in several mammalian species (Kel et al. 1999; J. Nardone, unpubl.). These observations are open to other interpretations, of course, because the Ras-MAP kinase pathway has abundant effects on other signaling proteins and transcription factors.

Transcriptional control of slow-twitch fiber differentiation: MyHC I gene expression during the transition from fast-twitch fiber to slow-twitch fiber is only one component of a global reprogramming that includes changes in other myofibrillar proteins; in proteins that release, bind, or sequester $\mathrm{Ca}^{2+}$; and in metabolic enzymes. It is natural to ask whether NFAT links $\mathrm{Ca}^{2+}$ signaling in skeletal muscle to a battery of genes characteristic of the slow-twitch fiber differentiation program, but the limited experimental evidence on this point has led to divergent interpretations /Chin et al. 1998; Calvo et al. 1999; Swoap et al. 2000; Wu et al. 2000). Broader participation of NFAT in control of slowtwitch fiber gene expression would not necessarily imply that NFAT is the preeminent input to each of the genes or that NFAT by itself triggers the differentiation program. Targets for further research will be to identify the particular promoters in the slow-twitch fiber differentiation program at which NFAT contributes to expression, and to explore how its contribution at these promoters is shaped by cell identity as reflected in chromatin structure, by cell history reflected in the complement of available transcription factors and cofactors, and by the specific context-normal development, altered activity, or regeneration-in which the slow-twitch fiber differentiation program is invoked.

\section{Conclusion}

In this review, we have developed two core themes: that the activation of NFAT proteins is determined by their phosphorylation state, which reflects the intensity of $\mathrm{Ca}^{2+} /$ calcineurin signaling and the activities of several kinases; and that transcriptionally active NFAT integrates inputs from multiple pathways through its interactions with partner proteins on DNA. The four calcium-regulated NFAT proteins diverged from NFAT5/ TonEBP, their nearest sibling in the Rel family, late in evolutionary history, by acquiring a regulatory region that provided a new channel for communication of intracellular $\mathrm{Ca}^{2+}$ signaling to DNA and by acquiring a new physical flexibility and novel protein contact surfaces that enabled them to cooperate with a variety of partner proteins in the nucleus. This molecular diversification coincided with the appearance of biological specializations that initiated the vertebrate lineage, and the new NFAT proteins took on a surprisingly varied set of specialized transcriptional roles. The detailed studies of NFAT function in $\mathrm{T}$ cells are an important starting point, but afford only a glimpse of the varied inputs and protein partners that are utilized by the four NFAT-family proteins in other biological contexts.

\section{Acknowledgments}

We thank Stefan Feske for an original version of Figure 1, and Stephen C. Harrison, Thomas Höfer, Riko Nishimura, Stefano Schiaffino, Martin F. Schneider, Mira Sǔsă, Tatsuo Takeya, and Erwin F. Wagner for discussions and unpublished data. A.R. acknowledges the support of the National Institutes of Health and the Sandler Program for Asthma Research. L.C. acknowledges the support of the National Institutes of Health and the W.M. Keck Foundation.

\section{References}

Abbott, K.L., Friday, B.B., Thaloor, D., Murphy, T.J., and Pavlath, G.K. 1998. Activation and cellular localization of the cyclosporine A-sensitive transcription factor NF-AT in skeletal muscle cells. Mol. Biol. Cell 9: 2905-2916.

Agalioti, T., Lomvardas, S., Parekh, B., Yie, J., Maniatis, T., and Thanos, D. 2000. Ordered recruitment of chromatin modifying and general transcription factors to the IFN- $\beta$ promoter. Cell 103: 667-678.

Agarwal, S., Avni, O., and Rao, A. 2000. Cell-type-restricted binding of the transcription factor NFAT to a distal IL-4 enhancer in vivo. Immunity 12: 643-652.

Al-Daraji, W.I., Grant, K.R., Ryan, K., Saxton, A., and Reynolds, N.J. 2002. Localization of calcineurin/NFAT in human skin and psoriasis and inhibition of calcineurin/NFAT activation in human keratinocytes by cyclosporin A. J. Invest. Dermatol. 118: 779-788.

Alcoléa, S., Thevéniau-Ruissy, M., Jarry-Guichard, T., Marics, I., Tzouanacou, E., Chauvin, J.P., Briand, J.P., Moorman, A.F., Lamers, W.H., and Gros, D.B. 1999. Downregulation of connexin 45 gene products during mouse heart development. Circ. Res. 84: 1365-1379.

Allen, D.L. and Leinwand, L.A. 2002. Intracellular calcium and myosin isoform transitions. Calcineurin and calciumcalmodulin kinase pathways regulate preferential activation of the IIa myosin heavy chain promoter. J. Biol. Chem. 277: 45323-45330. 
al Moustafa, A.E. and Chalifour, L.E. 1993. Immortal cell lines isolated from heart differentiate to an endothelial cell lineage in the presence of retinoic acid. Cell Growth Differ. 4: 841-847.

Ansel, M.K., Lee, D.U., and Rao, A. 2003. An epigenetic view of helper $\mathrm{T}$ cell differentiation. Nat. Immunol. 4: 616-623.

Anusaksathien, O., Laplace, C., Li, X., Ren, Y., Peng, L., Goldring, S.R., and Galson, D.L. 2001. Tissue-specific and ubiquitous promoters direct the expression of alternatively spliced transcripts from the calcitonin receptor gene. J. Biol. Chem. 276: 22663-22674.

Aramburu, J., Garcia-Cózar, F., Raghavan, A., Okamura, H., Rao, A., and Hogan, P.G. 1998. Selective inhibition of NFAT activation by a peptide spanning the calcineurin targeting site of NFAT. Mol. Cell 1: 627-637.

Aramburu, J., Yaffe, M.B., López-Rodríguez, C., Cantley, L.C., Hogan, P.G., and Rao, A. 1999. Affinity-driven peptide selection of an NFAT inhibitor more selective than cyclosporin A. Science 285: 2129-2133.

Armesilla, A.L., Lorenzo, E., Gómez del Arco, P., Martínez-Martínez, S., Alfranca, A., and Redondo, J.M. 1999. Vascular endothelial growth factor activates nuclear factor of activated $\mathrm{T}$ cells in human endothelial cells: A role for tissue factor gene expression. Mol. Cell. Biol. 19: 2032-2043.

Avni, O. and Rao, A. 2000. T cell differentiation: A mechanistic view. Curr. Opin. Immunol. 12: 654-659.

Avni, O., Lee, D., Macián, F., Szabo, S.J., Glimcher, L.H., and Rao, A. 2002. $\mathrm{T}(\mathrm{H})$ cell differentiation is accompanied by dynamic changes in histone acetylation of cytokine genes. Nat. Immunol. 3: 643-651.

Bakiri, L., Matsuo, K., Wisniewska, M., Wagner, E.F., and Yaniv, M. 2002. Promoter specificity and biological activity of tethered AP-1 dimers. Mol. Cell. Biol. 22: 4952-4964.

Baksh, S., Widlund, H.R., Frazer-Abel, A.A., Du, J., Fosmire, S., Fisher, D.E., DeCaprio, J.A., Modiano, J.F., and Burakoff, S.J. 2002. NFATc2-mediated repression of cyclin-dependent kinase 4 expression. Mol. Cell 10: 1071-1081.

Barton-Davis, E.R., LaFramboise, W.A., and Kushmerick, M.J. 1996. Activity-dependent induction of slow myosin gene expression in isolated fast-twitch mouse muscle. Am. I. Physiol. 271: C1409-C1414.

Beals, C.R., Clipstone, N.A., Ho, S.N., and Crabtree, G.R. 1997a. Nuclear localization of NF-ATc by a calcineurin-dependent, cyclosporin-sensitive intramolecular interaction. Genes \& Dev. 11: 824-834.

Beals, C.R., Sheridan, C.M., Turck, C.W., Gardner, P., and Crabtree, G.R. 1997b. Nuclear export of NF-ATc enhanced by glycogen synthase kinase-3. Science 275: 1930-1934.

Bert, A.G., Burrows, J., Hawwari, A., Vadas, M.A., and Cockerill, P.N. 2000. Reconstitution of T cell-specific transcription directed by composite NFAT/Oct elements. J. Immunol. 165: 5646-5655.

Bigard, X., Sanchez, H., Zoll, J., Mateo, P., Rousseau, V., Veksler, V., and Ventura-Clapier, R. 2000. Calcineurin co-regulates contractile and metabolic components of slow muscle phenotype. J. Biol. Chem. 275: 19653-19660.

Bodor, J., Bodorova, J., and Gress, R.E. 2000. Suppression of T cell function: A potential role for transcriptional repressor ICER. J. Leukocyte Biol. 67: 774-779.

Bower, K.E., Zeller, R.W., Wachsman, W., Martinez, T., and McGuire, K.L. 2002. Correlation of transcriptional repression by $21^{\mathrm{SNFT}}$ with changes in DNA.NF-AT complex interactions. J. Biol. Chem. 277: 34967-34977.

Bray, N., Dubchak, I., and Pachter, L. 2003. AVID: A global alignment program. Genome Res. 13: 97-102.

Brownson, C., Little, P., Mayne, C., Jarvis, J.C., and Salmons, S.
1992. Reciprocal changes in myosin isoform expression in rabbit fast skeletal muscle resulting from the application and removal of chronic electrical stimulation. Symp. Soc. Exp. Biol. 46: 301-310.

Bruneau, B.G. 2002. Transcriptional regulation of vertebrate cardiac morphogenesis. Circ. Res. 90: 509-519.

Brunet, A., Kanai, F., Stehn, J., Xu, J., Sarbassova, D., Frangioni, J.V., Dalal, S.N., DeCaprio, J.A., Greenberg, M.E., and Yaffe, M.B. 2002. 14-3-3 transits to the nucleus and participates in dynamic nucleocytoplasmic transport. J. Cell Biol. 156: 817 828; erratum 157: 533.

Burke, R.E., Levine, D.N., Zajac III, F.E., Tsairis, P., and Engel, W.K. 1971. Mammalian motor units: Physiological-histochemical correlation in three types in cat gastrocnemius. Science 174: 709-712.

Calvo, S., Venepally, P., Cheng, J., and Buonanno, A. 1999. Fiber-type-specific transcription of the troponin I slow gene is regulated by multiple elements. Mol. Cell. Biol. 19: 515525.

Cantrell, D. 2002. Protein kinase B (Akt) regulation and function in T lymphocytes. Sem. Immunol. 14: 19-26.

Cappellen, D., Luong-Nguyen, N.H., Bongiovanni, S., Grenet, O., Wanke, C., and Sǔsă, M. 2002. Transcriptional program of mouse osteoclast differentiation governed by the macrophage colony-stimulating factor and the ligand for the receptor activator of NFkB. J. Biol. Chem. 277: 21971-21982.

Carroll, S.L., Klein, M.G., and Schneider, M.F. 1997. Decay of calcium transients after electrical stimulation in rat fastand slow-twitch skeletal muscle fibres. J. Physiol. 501: 573588.

Carroll, S., Nicotera, P., and Pette, D. 1999. Calcium transients in single fibers of low-frequency stimulated fast-twitch muscle of rat. Am. J. Physiol. 277: C1122-C1129.

Chambers, T.J. 2000. Regulation of the differentiation and function of osteoclasts. J. Pathol. 192: 4-13.

Chen, C.H., Seguin-Devaux, C., Burke, N.A., Oriss, T. B., Watkins, S.C., Clipstone, N., and Ray, A. 2003. Transforming growth factor $\beta$ blocks Tee kinase phosphorylation, $\mathrm{Ca}^{2+}$ influx, and NFATc translocation causing inhibition of $\mathrm{T}$ cell differentiation. J. Exp. Med. 197: 1689-1699.

Chen, L., Oakley, M.G., Glover, J.N., Jain, J., Dervan, P.B., Hogan, P.G., Rao, A., and Verdine, G.L. 1995. Only one of the two DNA-bound orientations of AP-1 found in solution cooperates with NFATp. Curr. Biol. 5: 882-889.

Chen, L., Glover, J.N., Hogan, P.G., Rao, A., and Harrison, S.C. 1998. Structure of the DNA-binding domains from NFAT, Fos and Jun bound specifically to DNA. Nature 392: 42-48.

Chin, E.R., Olson, E.N., Richardson, J.A., Yang, Q., Humphries, C., Shelton, J.M., Wu, H., Zhu, W., Bassel-Duby, R., and Williams, R.S. 1998. A calcineurin-dependent transcriptional pathway controls skeletal muscle fiber type. Genes \& Dev. 12: 2499-2509.

Chinenov, Y. and Kerppola, T.K. 2001. Close encounters of many kinds: Fos-Jun interactions that mediate transcription regulatory specificity. Oncogene 20: 2438-2452.

Chow, C.W. and Davis, R.J. 2000. Integration of calcium and cyclic AMP signaling pathways by 14-3-3. Mol. Cell. Biol. 20: 702-712.

Chow, C.W., Rincón, M., Cavanagh, J., Dickens, M., and Davis, R.J. 1997. Nuclear accumulation of NFAT4 opposed by the JNK signal transduction pathway. Science 278: 16381641.

Chow, C.W., Rincón, M., and Davis, R.J. 1999. Requirement for transcription factor NFAT in interleukin-2 expression. Mol. Cell. Biol. 19: 2300-2307.

Chow, C.W., Dong, C., Flavell, R.A., and Davis, R.J. 2000. c-Jun 
$\mathrm{NH}_{2}$-terminal kinase inhibits targeting of the protein phosphatase calcineurin to NFATc1. Mol. Cell. Biol. 20: 52275234.

Chuvpilo, S., Zimmer, M., Kerstan, A., Glöckner, J., Avots, A., Escher, C., Fischer, C., Inashkina, I., Jankevics, E., BerberichSiebelt, F, et al. 1999. Alternative polyadenylation events contribute to the induction of NF-ATc in effector T cells. Immunity 10: 261-269.

Chuvpilo, S., Jankevics, E., Tyrsin, D., Akimzhanov, A., Moroz, D., Jha, M.K., Schulze-Luehrmann, J., Santner-Nanan, B., Feoktistova, E., König, T., et al. 2002. Autoregulation of NFATc1/A expression facilitates effector $\mathrm{T}$ cells to escape from rapid apoptosis. Immunity 16: 881-895.

Chytil, M. and Verdine, G.L. 1996. The Rel family of eukaryotic transcription factors. Curr. Opin. Struct. Biol. 6: 91-100.

Cockerill, P.N., Shannon, M.F., Bert, A.G., Ryan, G.R., and Vadas, M.A. 1993. The granulocyte-macrophage colony-stimulating factor/interleukin 3 locus is regulated by an inducible cyclosporin A-sensitive enhancer. Proc. Natl. Acad. Sci. 90: $2466-2470$.

Cockerill, P.N., Bert, A.G., Jenkins, F., Ryan, G.R., Shannon, M.F., and Vadas, M.A. 1995. Human granulocyte-macrophage colony-stimulating factor enhancer function is associated with cooperative interactions between AP-1 and NFATp/c. Mol. Cell. Biol. 15: 2071-2079.

Crabtree, G.R. and Olson, E.N. 2002. NFAT signaling: Choreographing the social lives of cells. Cell 109 Suppl: S67-S79.

Cross, D.A., Alessi, D.R., Cohen, P., Andjelkovich, M., and Hemmings, B.A. 1995. Inhibition of glycogen synthase kinase-3 by insulin mediated by protein kinase B. Nature 378: 785-789.

Davidson, E.H. 2001. Genomic regulatory systems: Development and evolution. Academic Press, Boston, MA.

Davis, R.J. 2000. Signal transduction by the JNK group of MAP kinases. Cell 103: 239-252.

Decker, E.L., Skerka, C., and Zipfel, P.F. 1998. The early growth response protein (EGR-1) regulates interleukin-2 transcription by synergistic interaction with the nuclear factor of activated T cells. J. Biol. Chem. 273: 26923-26930.

Decker, E.L., Nehmann, N., Kampen, E., Eibel, H., Zipfel, P.F., and Skerka, C. 2003. Early growth response proteins (EGR) and nuclear factors of activated $\mathrm{T}$ cells (NFAT) form heterodimers and regulate proinflammatory cytokine gene expression. Nucleic Acids Res. 31: 911-921.

de Gregorio, R., Iñiguez, M.A., Fresno, M., and Alemany, S. 2001. Cot kinase induces cyclooxygenase-2 expression in $\mathrm{T}$ cells through activation of the nuclear factor of activated $\mathrm{T}$ cells. J. Biol. Chem. 276: 27003-27009.

de la Pompa, J.L., Timmerman, L.A., Takimoto, H., Yoshida, H., Elia, A.J., Samper, E., Potter, J., Wakeham, A., Marengere, L., Langille, B.L., et al. 1998. Role of the NF-ATc transcription factor in morphogenesis of cardiac valves and septum. $\mathrm{Na}$ ture 392: 182-186.

Diehn, M., Alizadeh, A.A., Rando, O.J., Liu, C.L., Stankunas, K., Botstein, D., Crabtree, G.R., and Brown, P.O. 2002. Genomic expression programs and the integration of the CD28 costimulatory signal in T cell activation. Proc. Natl. Acad. Sci. 99: 11796-11801; erratum 99: 15245.

Dolmetsch, R.E., Lewis, R.S., Goodnow, C.C., and Healy, J.I. 1997. Differential activation of transcription factors induced by $\mathrm{Ca}^{2+}$ response amplitude and duration. Nature 386: 855858; erratum 388: 308.

Dolmetsch, R.E., Xu, K., and Lewis, R.S. 1998. Calcium oscillations increase the efficiency and specificity of gene expression. Nature 392: 933-936.

Dolmetsch, R.E., Pajvani, U., Fife, K., Spotts, J.M., and Green- berg, M.E. 2001. Signaling to the nucleus by an L-type calcium channel-calmodulin complex through the MAP kinase pathway. Science 294: 333-339.

Dor, Y., Camenisch, T.D., Itin, A., Fishman, G.I., McDonald, J.A., Carmeliet, P., and Keshet, E. 2001. A novel role for VEGF in endocardial cushion formation and its potential contribution to congenital heart defects. Development 128: $1531-1538$.

Dor, Y., Klewer, S.E., McDonald, J.A., Keshet, E., and Camenisch, T.D. 2003. VEGF modulates early heart valve formation. Anat. Rec. 271A: 202-208.

Duncliffe, K.N., Bert, A.G., Vadas, M.A., and Cockerill, P.N. 1997. A T cell-specific enhancer in the interleukin-3 locus is activated cooperatively by Oct and NFAT elements within a DNase I-hypersensitive site. Immunity 6: 175-185.

Dunn, S.E., Burns, J.L., and Michel, R.N. 1999. Calcineurin is required for skeletal muscle hypertrophy. J. Biol. Chem. 274: 21908-21912.

Dunn, S.E., Chin, E.R., and Michel, R.N. 2000. Matching of calcineurin activity to upstream effectors is critical for skeletal muscle fiber growth. J. Cell Biol. 151: 663-672.

Eisenberg, L.M. and Markwald, R.R. 1995. Molecular regulation of atrioventricular valvuloseptal morphogenesis. Circ. Res. 77: $1-6$.

Escalante, C.R., Shen, L., Thanos, D., and Aggarwal, A.K. 2002. Structure of NF-кB p50/p65 heterodimer bound to the PRDII DNA element from the interferon- $\beta$ promoter. Structure 10: 383-391.

Feske, S., Draeger, R., Peter, H.H., Eichmann, K., and Rao, A. 2000. The duration of nuclear residence of NFAT determines the pattern of cytokine expression in human SCID T cells. J. Immunol. 165: 297-305.

Feske, S., Giltnane, J., Dolmetsch, R., Staudt, L.M., and Rao, A. 2001. Gene regulation mediated by calcium signals in T lymphocytes. Nat. Immunol. 2: 316-324.

Fishman, M.C. and Chien, K.R. 1997. Fashioning the vertebrate heart: Earliest embryonic decisions. Development 124: 2099-2117.

Franzoso, G., Carlson, L., Xing, L., Poljak, L., Shores, E.W., Brown, K.D., Leonardi, A., Tran, T., Boyce, B.F., and Siebenlist, U. 1997. Requirement for Nf-кB in osteoclast and B-cell development. Genes \& Dev. 11: 3482-3496.

Frey, N. and Olson, E.N. 2002. Calsarcin-3, a novel skeletal muscle-specific member of the calsarcin family, interacts with multiple Z-disc proteins. J. Biol. Chem. 277: 1399814004.

Frey, N., Richardson, J.A., and Olson, E.N. 2000. Calsarcins, a novel family of sarcomeric calcineurin-binding proteins. Proc. Natl. Acad. Sci. 97: 14632-14637.

Fuentes, J.J., Genescà, L., Kingsbury, T.J., Cunningham, K.W., Pérez-Riba, M., Estivill, X., and de la Luna, S. 2000. DSCR1, overexpressed in Down syndrome, is an inhibitor of calcineurin-mediated signaling pathways. Hum. Mol. Genet. 9: $1681-1690$.

Fürstenau, U., Schwaninger, M., Blume, R., Jendrusch, E.M., and Knepel, W. 1999. Characterization of a novel calcium response element in the glucagon gene. J. Biol. Chem. 274: 5851-5860.

Garrity, P.A., Chen, D., Rothenberg, E.V., and Wold, B.J. 1994. Interleukin-2 transcription is regulated in vivo at the level of coordinated binding of both constitutive and regulated factors. Mol. Cell. Biol. 14: 2159-2169.

Ghosh, G., van Duyne, G., Ghosh, S., and Sigler, P.B. 1995. Structure of NF-кB p50 homodimer bound to a $\kappa \mathrm{B}$ site. $\mathrm{Na}$ ture 373: 303-310.

Giffin, M.J., Stroud, J.C., Bates, D., von Koenig, K.D., Hardin, J., 
and Chen, L. 2003. Structure of NFAT1 bound as a dimer to the HIV-1 LTR кB element. Nat. Struct. Biol. (in press).

Giger, J.M., Haddad, F., Qin, A.X., and Baldwin, K.M. 2000. In vivo regulation of the $\beta$-myosin heavy chain gene in soleus muscle of suspended and weight-bearing rats. Am. J. Physiol. Cell Physiol. 278: C1153-C1161.

Glimcher, L.H. and Murphy, K.M. 2000. Lineage commitment in the immune system: The T helper lymphocyte grows up. Genes \& Dev. 14: 1693-1711.

Goldfeld, A.E., McCaffrey, P.G., Strominger, J.L., and Rao, A. 1993. Identification of a novel cyclosporin-sensitive element in the human tumor necrosis factor $\alpha$ gene promoter. J. Exp. Med. 178: 1365-1379.

Gómez del Arco, P., Martínez-Martínez, S., Maldonado, J.L., Ortega-Pérez, I., and Redondo, J.M. 2000. A role for the p38 MAP kinase pathway in the nuclear shuttling of NFATp. $J$. Biol. Chem. 275: 13872-13878.

Graef, I.A., Mermelstein, P.G., Stankunas, K., Neilson, J.R., Deisseroth, K., Tsien, R.W., and Crabtree, G.R. 1999. L-type calcium channels and GSK-3 regulate the activity of NF-ATc4 in hippocampal neurons. Nature 401: 703708.

Graef, I.A., Chen, F., Chen, L., Kuo, A., and Crabtree, G.R. 2001a. Signals transduced by $\mathrm{Ca}^{2+} /$ calcineurin and NFATc3/c4 pattern the developing vasculature. Cell 105: 863 875.

Graef, I.A., Gastier, J.M., Francke, U., and Crabtree, G.R. 2001 b. Evolutionary relationships among Rel domains indicate functional diversification by recombination. Proc. Natl. Acad. Sci. 98: 5740-5745.

Graef, I.A., Wang, F., Frederic, C., Chen, L., Neilson, J., TessierLavigne, M., and Crabtree, G.R. 2003. Neurotrophins and netrins require calcineurin/NFAT signaling to stimulate outgrowth of embryonic axons. Cell 113: 657-670.

Grigoriadis, A.E., Wang, Z.Q., Cecchini, M.G., Hofstetter, W., Felix, R., Fleisch, H.A., and Wagner, E.F. 1994. c-Fos: A key regulator of osteoclast-macrophage lineage determination and bone remodeling. Science 266: 443-448.

Harwood, A.J. 2001. Regulation of GSK-3: A cellular multiprocessor. Cell 105: 821-824.

Hattersley, G. and Chambers, T.J. 1989. Calcitonin receptors as markers for osteoclastic differentiation: Correlation between generation of bone-resorptive cells and cells that express calcitonin receptors in mouse bone marrow cultures. Endocrinology 125: 1606-1612.

Hawwari, A., Burrows, J., Vadas, M.A., and Cockerill, P.N. 2002. The human IL-3 locus is regulated cooperatively by two NFAT-dependent enhancers that have distinct tissuespecific activities. J. Immunol. 169: 1876-1886.

Hernández, G.L., Volpert, O.V., Iñiguez, M.A., Lorenzo, E., Martínez-Martínez, S., Grau, R., Fresno, M., and Redondo, J.M. 2001. Selective inhibition of vascular endothelial growth factor-mediated angiogenesis by cyclosporin A: Roles of the nuclear factor of activated $\mathrm{T}$ cells and cyclooxygenase 2. $J$. Exp. Med. 193: 607-620.

Hill-Eubanks, D.C., Gomez, M.F., Stevenson, A.S., and Nelson, M.T. 2003. NFAT regulation in smooth muscle. Trends Cardiovasc. Med. 13: 56-62.

Ho, I.C., Hodge, M.R., Rooney, J.W., and Glimcher, L.H. 1996. The proto-oncogene c-maf is responsible for tissue-specific expression of interleukin-4. Cell 85: 973-983.

Ho, S.N., Thomas, D.J., Timmerman, L.A., Li, X., Francke, U., and Crabtree, G.R. 1995. NFATc3, a lymphoid-specific NFATc family member that is calcium-regulated and exhibits distinct DNA binding specificity. J. Biol. Chem. 270: $19898-19907$.
Hoey, T., Sun, Y.L., Williamson, K., and Xu, X. 1995. Isolation of two new members of the NF-AT gene family and functional characterization of the NF-AT proteins. Immunity 2: 461-472.

Horsley, V. and Pavlath, G.K. 2002. NFAT: Ubiquitous regulator of cell differentiation and adaptation. I. Cell Biol. 156: 771-774.

Hove, J.R., Köster, R.W., Forouhar, A.S, Acevedo-Bolton, G., Fraser, S.E., and Gharib, M. 2003. Intracardiac fluid forces are an essential epigenetic factor for embryonic cardiogenesis. Nature 421: 172-177.

Hsu, H., Lacey, D.L., Dunstan, C.R., Solovyev, I., Colombero, A., Timms, E., Tan, H.L., Elliott, G., Kelley, M.J., Sarosi, I., et al. 1999. Tumor necrosis factor receptor family member RANK mediates osteoclast differentiation and activation induced by osteoprotegerin ligand. Proc. Natl. Acad. Sci. 96: $3540-3545$.

Hu, C.M., Jang, S.Y., Fanzo, J.C., and Pernis, A.B. 2002. Modulation of $\mathrm{T}$ cell cytokine production by interferon regulatory factor-4. J. Biol. Chem. 277: 49238-49246.

Huang, W.Y. and Liew, C.C. 1998. Chromatin remodelling of the cardiac $\beta$-myosin heavy chain gene. Biochem. $J$. 330: $871-876$.

Huang, W.Y., Chen, J.J., Shih, N., and Liew, C.C. 1997. Multiple muscle-specific regulatory elements are associated with a DNase I hypersensitive site of the cardiac $\beta$-myosin heavychain gene. Biochem. J. 327: 507-512.

Huxford, T., Huang, D.B., Malek, S., and Ghosh, G. 1998. The crystal structure of the I $\kappa \mathrm{B} \alpha / \mathrm{NF}-\kappa \mathrm{B}$ complex reveals mechanisms of NF-кB inactivation. Cell 95: 759-770.

Irintchev, A., Zweyer, M., Cooper, R.N., Butler-Browne, G.S., and Wernig, A. 2002. Contractile properties, structure and fiber phenotype of intact and regenerating slow-twitch muscles of mice treated with cyclosporin A. Cell \& Tissue Res. 308: 143-156.

Ishida, N., Hayashi, K., Hoshijima, M., Ogawa, T., Koga, S., Miyatake, Y., Kumegawa, M., Kimura, T., and Takeya, T. 2002. Large scale gene expression analysis of osteoclastogenesis in vitro and elucidation of NFAT2 as a key regulator. $J$. Biol. Chem. 277: 41147-41156.

Jacobs, M.D. and Harrison, S.C. 1998. Structure of an IkB $\alpha /$ NFкB complex. Cell 95: 749-758.

Jain, J., McCaffrey, P.G., Valge-Archer, V.E., and Rao, A. 1992. Nuclear factor of activated $\mathrm{T}$ cells contains Fos and Jun. Nature 356: 801-804.

Jain, J., McCaffrey, P.G., Miner, Z., Kerppola, T.K., Lambert, J.N., Verdine, G.L., Curran, T., and Rao, A. 1993a. The T-cell transcription factor NFATp is a substrate for calcineurin and interacts with Fos and Jun. Nature 365: 352-355.

Jain, J.N., Miner, Z., and Rao, A. 1993b. Analysis of the preexisting and nuclear forms of nuclear factor of activated $\mathrm{T}$ cells. J. Immunol. 151: 837-848.

Jauliac, S., López-Rodríguez, C., Shaw, L.M., Brown, L.F., Rao, A., and Toker, A. 2002. The role of NFAT transcription factors in integrin-mediated carcinoma invasion. Nat. Cell Biol. 4: 540-544.

Jin, L., Sliz, P., Chen, L., Macián, F., Rao, A., Hogan, P.G., and Harrison, S.C. 2003. An asymmetric NFAT1 dimer on a pseudo-palindromic кB-like DNA site. Nat. Struct. Biol. (in press).

Jochum, W., Passegue, E., and Wagner, E.F. 2001. AP-1 in mouse development and tumorigenesis. Oncogene 20: 24012412.

Johnson, E.N., Lee, Y.M., Sander, T.L., Rabkin, E., Schoen, F.J., Kaushal, S., and Bischoff, J. 2003. NFATc1 mediates vascular endothelial growth factor-induced proliferation of human 
pulmonary valve endothelial cells. J. Biol. Chem. 278: 16861692.

Kaminuma, O., Deckert, M., Elly, C., Liu, Y.C., and Altman, A. 2001. Vav-Rac1-mediated activation of the c-Jun N-terminal kinase/c-Jun/AP-1 pathway plays a major role in stimulation of the distal NFAT site in the interleukin-2 gene promoter. Mol. Cell. Biol. 21: 3126-3136.

Kehlenbach, R.H., Dickmanns, A., and Gerace, L. 1998. Nucleocytoplasmic shuttling factors including Ran and CRM1 mediate nuclear export of NFAT in vitro. J. Cell Biol. 141: 863-874.

Kel, A., Kel-Margoulis, O., Babenko, V., and Wingender, E. 1999. Recognition of NFATp/AP-1 composite elements within genes induced upon the activation of immune cells. J. Mol. Biol. 288: 353-376.

Kiani, A., Rao, A., and Aramburu, J. 2000. Manipulating immune responses with immunosuppressive agents that target NFAT. Immunity 12: 359-372.

Kim, R.Y., Robertson, E.J., and Solloway, M.J. 2001. Bmp6 and Bmp7 are required for cushion formation and septation in the developing mouse heart. Dev. Biol. 235: 449-466.

Kingsbury, T.J. and Cunningham, K.W. 2000. A conserved family of calcineurin regulators. Genes \& Dev. 14: 15951604.

Kirschbaum, B.J., Schneider, S., Izumo, S., Mahdavi, V., NadalGinard, B., and Pette, D. 1990. Rapid and reversible changes in myosin heavy chain expression in response to increased neuromuscular activity of rat fast-twitch muscle. FEBS Lett. 268: $75-78$.

Klemm, J.D., Beals, C.R., and Crabtree, G.R. 1997. Rapid targeting of nuclear proteins to the cytoplasm. Curr. Biol. 7: 638-644.

Knotts, S., Sanchez, A., Rindt, H., and Robbins, J. 1996. Developmental modulation of a $\beta$ myosin heavy chain promoterdriven transgene. Dev. Dyn. 206: 182-192.

Kubis, H.P., Haller, E.A., Wetzel, P., and Gros, G. 1997. Adult fast myosin pattern and $\mathrm{Ca}^{2+}$-induced slow myosin pattern in primary skeletal muscle culture. Proc. Natl. Acad. Sci. 94: 4205-4210.

Kubis, H.P., Scheibe, R.J., Meißner, J.D., Hornung, G., and Gros, G. 2002. Fast-to-slow transformation and nuclear import/ export kinetics of the transcription factor NFATc1 during electrostimulation of rabbit muscle cells in culture. $J$. Physiol. 541: 835-847.

Kubis, H.P., Hanke, N., Scheibe, R.J., Meißner, J.D., and Gros, G. 2003. $\mathrm{Ca}^{2+}$ transients activate calcineurin/NFATc1 and initiate fast-to-slow transformation in a primary skeletal muscle culture. Am. J. Physiol. Cell Physiol. 285: C56C63.

Kumai, M., Nishii, K., Nakamura, K., Takeda, N., Suzuki, M., and Shibata, Y. 2000. Loss of connexin45 causes a cushion defect in early cardiogenesis. Development 127:35013512.

Kurihara, Y., Kurihara, H., Oda, H., Maemura, K., Nagai, R., Ishikawa, T., and Yazaki, Y. 1995. Aortic arch malformations and ventricular septal defect in mice deficient in endothelin-1. J. Clin. Invest. 96: 293-300.

Lacey, D.L., Timms, E., Tan, H.L., Kelley, M.J., Dunstan, C.R., Burgess, T., Elliott, R., Colombero, A., Elliott, G., Scully, S., et al. 1998. Osteoprotegerin ligand is a cytokine that regulates osteoclast differentiation and activation. Cell 93: 165176.

Lakshmanan, G., Lieuw, K.H., Lim, K.C., Gu, Y., Grosveld, F., Engel, J.D., and Karis, A. 1999. Localization of distant urogenital system-, central nervous system-, and endocardiumspecific transcriptional regulatory elements in the GATA-3 locus. Mol. Cell. Biol. 19: 1558-1568.
Lee, H.J., Masuda, E.S., Arai, N., Arai, K., and Yokota, T. 1995. Definition of cis-regulatory elements of the mouse interleukin-5 gene promoter. Involvement of nuclear factor of activated $\mathrm{T}$ cell-related factors in interleukin-5 expression. $J$. Biol. Chem. 270: 17541-17550.

Lefstin, J.A. and Yamamoto, K.R. 1998. Allosteric effects of DNA on transcriptional regulators. Nature 392: 885-888.

Li, W., Llopis, J., Whitney, M., Zlokarnik, G., and Tsien, R.Y. 1998. Cell-permeant caged InsP3 ester shows that $\mathrm{Ca}^{2+}$ spike frequency can optimize gene expression. Nature 392: 936941.

Liu, J., Masuda, E.S., Tsuruta, L., Arai, N., and Arai, K. 1999. Two independent calcineurin-binding regions in the $\mathrm{N}$-terminal domain of murine NF-ATx1 recruit calcineurin to murine NF-ATx1. J. Immunol. 162: 4755-4761.

Liu, J., Arai, K., and Arai, N. 2001. Inhibition of NFATx activation by an oligopeptide: Disrupting the interaction of NFATx with calcineurin. J. Immunol. 167: 2677-2687.

Liu, W., Youn, H.D., Zhou, X.Z., Lu, K.P., and Liu, J.O. 2001. Binding and regulation of the transcription factor NFAT by the peptidyl prolyl cis-trans isomerase Pin1. FEBS Lett. 496: 105-108.

Liu, Y. and Schneider, M.F. 1998. Fibre type-specific gene expression activated by chronic electrical stimulation of adult mouse skeletal muscle fibres in culture. J. Physiol. 512: 337344.

Liu, Y., Cseresnyes, Z., Randall, W.R., and Schneider, M.F. 2001. Activity-dependent nuclear translocation and intranuclear distribution of NFATc in adult skeletal muscle fibers. J. Cell Biol. 155: 27-39.

Loh, C., Carew, J.A., Kim, J., Hogan, P.G., and Rao, A. 1996a. $\mathrm{T}$-cell receptor stimulation elicits an early phase of activation and a later phase of deactivation of the transcription factor NFAT1. Mol. Cell. Biol. 16: 3945-3954.

Loh, C., Shaw, K.T., Carew, J., Viola, J.P., Luo, C., Perrino, B.A., and Rao, A. 1996b. Calcineurin binds the transcription factor NFAT1 and reversibly regulates its activity. J. Biol. Chem. 271: 10884-10891.

Loots, G.G., Ovcharenko, I., Pachter, L., Dubchak, I., and Rubin, E.M. 2002. rVista for comparative sequence-based discovery of functional transcription factor binding sites. Genome Res. 12: $832-839$.

López-Rodríguez, C., Aramburu, J., Rakeman, A.S., and Rao, A. 1999. NFAT5, a constitutively nuclear NFAT protein that does not cooperate with Fos and Jun. Proc. Natl. Acad. Sci. 96: 7214-7219.

López-Rodríguez, C., Aramburu, J., Jin, L., Rakeman, A.S., Michino, M., and Rao, A. 2001. Bridging the NFAT and NF$\kappa \mathrm{B}$ families: NFAT5 dimerization regulates cytokine gene transcription in response to osmotic stress. Immunity 15: 47-58.

Macián, F., López-Rodríguez, C., and Rao, A. 2001. Partners in transcription: NFAT and AP-1. Oncogene 20: 2476-2489.

Macián, F., Garciá-Cózar, F., Im, S.H., Horton, H.F., Byrne, M.C., and Rao, A. 2002. Transcriptional mechanisms underlying lymphocyte tolerance. Cell 109: 719-731.

Masuda, E.S., Naito, Y., Tokumitsu, H., Campbell, D., Saito, F., Hannum, C., Arai, K.I., and Arai, N. 1995. Nfatx, a novel member of the nuclear factor of activated $\mathrm{T}$ cells family that is expressed predominantly in the thymus. Mol. Cell. Biol. 15: 2697-2706.

Mayor, C., Brudno, M., Schwartz, J.R., Poliakov, A., Rubin, E.M., Frazer, K.A., Pachter, L.S., and Dubchak, I. 2000. VISTA: Visualizing global DNA sequence alignments of arbitrary length. Bioinformatics 16: 1046-1047.

McCaffrey, P.G., Luo, C., Kerppola, T.K., Jain, J., Badalian, T.M., 
Ho, A.M., Burgeon, E., Lane, W.S., Lambert, J.N., Curran, T., et al. 1993. Isolation of the cyclosporin-sensitive T cell transcription factor NFATp. Science 262: 750-754.

McCaffrey, P.G., Goldfeld, A.E., and Rao, A. 1994. The role of NFATp in cyclosporin A-sensitive tumor necrosis factor- $\alpha$ gene transcription. J. Biol. Chem. 269: 30445-30450.

McFadden, D.G. and Olson, E.N. 2002. Heart development: Learning from mistakes. Curr. Opin. Genet. Dev. 12: 328335.

McKinsey, T.A., Zhang, C.L., and Olson, E.N. 2002. MEF2: A calcium-dependent regulator of cell division, differentiation and death. Trends Biochem. Sci. 27: 40-47.

Mechta-Grigoriou, F., Gerald, D., and Yaniv, M. 2001. The mammalian Jun proteins: Redundancy and specificity. Oncogene 20: 2378-2389.

Meißner, J.D., Kubis, H.P., Scheibe, R.J., and Gros, G. 2000. Reversible $\mathrm{Ca}^{2+}$-induced fast-to-slow transition in primary skeletal muscle culture cells at the mRNA level. J. Physiol. 523: 19-28.

Meißner, J.D., Gros, G., Scheibe, R.J., Scholz, M., and Kubis, H.P. 2001. Calcineurin regulates slow myosin, but not fast myosin or metabolic enzymes, during fast-to-slow transformation in rabbit skeletal muscle cell culture. J. Physiol. 533: 215-226.

Meiyanto, E., Hoshijima, M., Ogawa, T., Ishida, N., and Takeya, T. 2001. Osteoclast differentiation factor modulates cell cycle machinery and causes a delay in $S$ phase progression in RAW264 cells. Biochem. Biophys. Res. Commun. 282: 278 283.

Miskin, J.E., Abrams, C.C., and Dixon, L.K. 2000. African swine fever virus protein A238L interacts with the cellular phosphatase calcineurin via a binding domain similar to that of NFAT. J. Virology 74: 9412-9420.

Miyakawa, H., Woo, S.K., Dahl, S.C., Handler, J.S., and Kwon, H.M. 1999. Tonicity-responsive enhancer binding protein, a rel-like protein that stimulates transcription in response to hypertonicity. Proc. Natl. Acad. Sci. 96: 2538-2542.

Molkentin, J.D., Lu, J.R., Antos, C.L., Markham, B., Richardson, J., Robbins, J., Grant, S.R., and Olson, E.N. 1998. A calcineurin-dependent transcriptional pathway for cardiac hypertrophy. Cell 93: 215-228.

Monticelli, S. and Rao, A. 2002. NFAT1 and NFAT2 are positive regulators of IL-4 gene transcription. Eur. I. Immunol. 32: 2971-2978.

Morimoto, T., Hasegawa, K., Wada, H., Kakita, T., Kaburagi, S., Yanazume, T., and Sasayama, S. 2001. Calcineurin-GATA4 pathway is involved in $\beta$-adrenergic agonist-responsive endothelin-1 transcription in cardiac myocytes. J. Biol. Chem. 276: 34983-34989.

Morrisey, E.E., Ip, H.S., Tang, Z., Lu, M.M., and Parmacek, M.S. 1997. GATA-5: A transcriptional activator expressed in a novel temporally and spatially-restricted pattern during embryonic development. Dev. Biol. 183: 21-36.

Muller, C.W., Rey, F.A., Sodeoka, M., Verdine, G.L., and Harrison, S.C. 1995. Structure of the NF-к B p50 homodimer bound to DNA. Nature 373: 311-317.

Murgia, M., Serrano, A.L., Calabria, E., Pallafacchina, G., Lømo, T., and Schiaffino, S. 2000. Ras is involved in nerve-activitydependent regulation of muscle genes. Nat. Cell Biol. 2: $142-147$.

Musaro, A., McCullagh, K.J., Naya, F.J., Olson, E.N., and Rosenthal, N. 1999. IGF-1 induces skeletal myocyte hypertrophy through calcineurin in association with GATA-2 and NFATc1. Nature 400: 581-585.

Nash, P., Tang, X., Orlicky, S., Chen, Q., Gertler, F.B., Mendenhall, M.D., Sicheri, F., Pawson, T., and Tyers, M. 2001. Mul- tisite phosphorylation of a CDK inhibitor sets a threshold for the onset of DNA replication. Nature 414: 514-521.

Neal, J.W. and Clipstone, N.A. 2001. Glycogen synthase kinase-3 inhibits the DNA binding activity of NFATc. J. Biol. Chem. 276: 3666-3673.

Nemer, G. and Nemer, M. 2002. Cooperative interaction between GATA5 and NF-ATc regulates endothelial-endocardial differentiation of cardiogenic cells. Development 129: 4045-4055.

Northrop, J.P., Ho, S.N., Chen, L., Thomas, D.J., Timmerman, L.A., Nolan, G.P., Admon, A., and Crabtree, G.R. 1994. NFAT components define a family of transcription factors targeted in T-cell activation. Nature 369: 497-502.

Okamura, H., Aramburu, J., García-Rodríguez, C., Viola, J.P., Raghavan, A., Tahiliani, M., Zhang, X., Qin, J., Hogan, P.G., and Rao, A. 2000. Concerted dephosphorylation of the transcription factor NFAT1 induces a conformational switch that regulates transcriptional activity. Mol. Cell 6: 539550.

Olson, E.N. and Williams, R.S. 2000. Remodeling muscles with calcineurin. Bioessays 22: 510-519; erratum 22: 1049.

Orcel, P., Denne, M.A., and de Vernejoul, M.C. 1991. Cyclosporin-A in vitro decreases bone resorption, osteoclast formation, and the fusion of cells of the monocyte-macrophage lineage. Endocrinology 128: 1638-1646.

Orlicky, S., Tang, X., Willems, A., Tyers, M., and Sicheri, F. 2003. Structural basis for phosphodependent substrate selection and orientation by the $\mathrm{SCF}^{\mathrm{Cdc} 4}$ ubiquitin ligase. Cell 112: $243-256$.

Osborne, C.S., Vadas, M.A., and Cockerill, P.N. 1995. Transcriptional regulation of mouse granulocyte-macrophage colony-stimulating factor/IL-3 locus. J. Immunol. 155: 226235.

Pallafacchina, G., Calabria, E., Serrano, A.L., Kalhovde, J.M., and Schiaffino, S. 2002. A protein kinase B-dependent and rapamycin-sensitive pathway controls skeletal muscle growth but not fiber type specification. Proc. Natl. Acad. Sci. 99: 9213-9218.

Park, S., Uesugi, M., and Verdine, G.L. 2000. A second calcineurin binding site on the NFAT regulatory domain. Proc. Nat1. Acad. Sci. 97: 7130-7135.

Parry, R.V., Reif, K., Smith, G., Sansom, D.M., Hemmings, B.A., and Ward, S.G. 1997. Ligation of the T cell co-stimulatory receptor $\mathrm{CD} 28$ activates the serine-threonine protein kinase protein kinase B. Eur. J. Immunol. 27: 2495-2501.

Peng, S.L., Gerth, A.J., Ranger, A.M., and Glimcher, L.H. 2001. NFATc1 and NFATc2 together control both $T$ and $B$ cell activation and differentiation. Immunity 14: 13-20.

Peterson, B.R., Sun, L.J., and Verdine, G.L. 1996. A critical arginine residue mediates cooperativity in the contact interface between transcription factors NFAT and AP-1. Proc. Natl. Acad. Sci. 93: 13671-13676.

Pette, D. and Staron, R.S. 2000. Myosin isoforms, muscle fiber types, and transitions. Microscopy Res. Tech. 50: 500-509.

Peuker, H. and Pette, D. 1995. Reverse transcriptase-polymerase chain reaction detects induction of cardiac-like $\alpha$ myosin heavy chain mRNA in low frequency stimulated rabbit fasttwitch muscle. FEBS Lett. 367: 132-136.

Peuker, H., Conjard, A., Putman, C.T., and Pette, D. 1999. Transient expression of myosin heavy chain MHCI $\alpha$ in rabbit muscle during fast-to-slow transition. J. Muscle Res. Cell Motility 20: 147-154.

Porter, C.M. and Clipstone, N.A. 2002. Sustained NFAT signaling promotes a Th1-like pattern of gene expression in primary murine CD4+ T cells. J. Immunol. 168: 4936-4945.

Porter, C.M., Havens, M.A., and Clipstone, N.A. 2000. Identi- 
fication of amino acid residues and protein kinases involved in the regulation of NFATc subcellular localization. J. Biol. Chem. 275: 3543-3551.

Rainio, E.M., Sandholm, J., and Koskinen, P.J. 2002. Cutting edge: Transcriptional activity of NFATc1 is enhanced by the Pim-1 kinase. J. Immunol. 168: 1524-1527.

Ranger, A.M., Grusby, M.J., Hodge, M.R., Gravallese, E.M., de la Brousse, F.C., Hoey, T., Mickanin, C., Baldwin, H.S., and Glimcher, L.H. 1998a. The transcription factor NF-ATc is essential for cardiac valve formation. Nature 392: 186190.

Ranger, A.M., Oukka, M., Rengarajan, J., and Glimcher LH. 1998b. Inhibitory function of two NFAT family members in lymphoid homeostasis and Th2 development. Immunity 9: 627-635.

Rao, A., Luo, C., and Hogan, P.G. 1997. Transcription factors of the NFAT family: Regulation and function. Annu. Rev. Immunol. 15: 707-747.

Rengarajan, J., Mowen, K.A., McBride, K.D., Smith, E.D., Singh, H., and Glimcher, L.H. 2002. Interferon regulatory factor 4 (IRF4) interacts with NFATc2 to modulate interleukin 4 gene expression. J. Exp. Med. 195: 1003-1012.

Rindt, H., Gulick, J., Knotts, S., Neumann, J., and Robbins, J. 1993. In vivo analysis of the murine $\beta$-myosin heavy chain gene promoter. J. Biol. Chem. 268: 5332-5338.

Rooney, J.W., Hoey, T., and Glimcher, L.H. 1995. Coordinate and cooperative roles for NF-AT and AP-1 in the regulation of the murine IL-4 gene. Immunity 2: 473-483.

Rothermel, B., Vega, R.B., Yang, J., Wu, H., Bassel-Duby, R., and Williams, R.S. 2000. A protein encoded within the Down syndrome critical region is enriched in striated muscles and inhibits calcineurin signaling. J. Biol. Chem. 275: 87198725.

Rothwarf, D.M. and Karin, M. 1999. The NF-кB activation pathway: A paradigm in information transfer from membrane to nucleus. Science's Stke: Signal Transduction Knowledge Environment 1999: RE1.

Salazar, C. and Höfer, T. 2003. Allosteric regulation of the transcription factor NFAT1 by multiple phosphorylation sites: A mathematical analysis. J. Mol. Biol. 327: 31-45.

Schiaffino, S. and Serrano, A. 2002. Calcineurin signaling and neural control of skeletal muscle fiber type and size. Trends Pharmacol. Sci. 23: 569-575.

Schwartz, S., Zhang, Z., Frazer, K.A., Smit, A., Riemer, C., Bouck, J., Gibbs, R., Hardison, R., and Miller, W. 2000. PipMaker-A Web server for aligning two genomic DNA sequences. Genome Res. 10: 577-586.

Scully, K.M., Jacobson, E.M., Jepsen, K., Lunyak, V., Viadiu, H., Carrière, C., Rose, D.W., Hooshmand, F., Aggarwal, A.K., and Rosenfeld, M.G. 2000. Allosteric effects of Pit-1 DNA sites on long-term repression in cell type specification. Science 290: 1127-1131.

Serfling, E., Berberich-Siebelt, F., Chuvpilo, S., Jankevics, E., Klein-Hessling, S., Twardzik, T., and Avots, A. 2000. The role of NF-AT transcription factors in $\mathrm{T}$ cell activation and differentiation. Biochim. Biophys. Acta. 1498: 1-18.

Serrano, A.L., Murgia, M., Pallafacchina, G., Calabria, E., Coniglio, P., Lømo, T., and Schiaffino, S. 2001. Calcineurin controls nerve activity-dependent specification of slow skeletal muscle fibers but not muscle growth. Proc. Natl. Acad. Sci. 98: $13108-13113$.

Shaw, K.T., Ho, A.M., Raghavan, A., Kim, J., Jain, J., Park, J., Sharma, S., Rao, A., and Hogan, P.G. 1995. Immunosuppressive drugs prevent a rapid dephosphorylation of transcription factor NFAT1 in stimulated immune cells. Proc. Natl. Acad. Sci. 92: 11205-11209.
Sheridan, C.M., Heist, E.K., Beals, C.R., Crabtree, G.R., and Gardner, P. 2002. Protein kinase A negatively modulates the nuclear accumulation of NF-ATc1 by priming for subsequent phosphorylation by glycogen synthase kinase-3. I. Biol. Chem. 277: 48664-48676.

Shibasaki, F., Price, E.R., Milan, D., and McKeon, F. 1996. Role of kinases and the phosphatase calcineurin in the nuclear shuttling of transcription factor NF-AT4. Nature 382: 370373

Shui, C., Riggs, B.L., and Khosla, S. 2002. The immunosuppressant rapamycin, alone or with transforming growth factor- $\beta$, enhances osteoclast differentiation of RAW264.7 monocytemacrophage cells in the presence of RANK-ligand. Calcified Tissue Int1. 71: 437-446.

Siebenlist, U., Durand, D.B., Bressler, P., Holbrook, N.J., Norris, C.A., Kamoun, M., Kant, J.A., and Crabtree, G.R. 1986. Promoter region of interleukin-2 gene undergoes chromatin structure changes and confers inducibility on chloramphenicol acetyltransferase gene during activation of T cells. Mol. Cell. Biol. 6: 3042-3049.

Solymar, D.C., Agarwal, S., Bassing, C.H., Alt, F.W., and Rao, A. 2002. A 3' enhancer in the IL-4 gene regulates cytokine production by Th2 cells and mast cells. Immunity 17: 41-50.

Sosinowski, T., Pandey, A., Dixit, V.M., and Weiss, A. 2000. Src-like adaptor protein (SLAP) is a negative regulator of $\mathrm{T}$ cell receptor signaling. J. Exp. Med. 191: 463-474.

Sreter, F.A., Lopez, J.R., Alamo, L., Mabuchi, K., and Gergely, J. 1987. Changes in intracellular ionized Ca concentration associated with muscle fiber type transformation. Am. J. Physiol. 253: C296-C300.

Stevenson, A.S., Gomez, M.F., Hill-Eubanks, D.C., and Nelson, M.T. 2001. NFAT4 movement in native smooth muscle. A role for differential $\mathrm{Ca}^{2+}$ signaling. J. Biol. Chem. 276: 15018-15024.

Stroud, J.C., López-Rodríguez, C., Rao, A., and Chen, L. 2002. Structure of a TonEBP-DNA complex reveals DNA encircled by a transcription factor. Nat. Struct. Biol. 9: 90-94.

Sucov, H.M. 1998. Molecular insights into cardiac development. Ann. Rev. Physiol. 60: 287-308.

Swoap, S.J., Hunter, R.B., Stevenson, E.J., Felton, H.M., Kansagra, N.V., Lang, J.M., Esser, K.A., and Kandarian, S.C. 2000. The calcineurin-NFAT pathway and muscle fiber-type gene expression. Am. J. Physiol. Cell Physiol. 279: C915C924.

Takayanagi, H., Kim, S., Koga, T., Nishina, H., Isshiki, M., Yoshida, H., Saiura, A., Isobe, M., Yokochi, T., Inoue, J., et al. 2002. Induction and activation of the transcription factor NFATc1 (NFAT2) integrate RANKL signaling in terminal differentiation of osteoclasts. Dev. Cell 3: 889-901.

Teitelbaum, S.L. 2000. Bone resorption by osteoclasts. Science 289: $1504-1508$.

Timmerman, L.A., Clipstone, N.A., Ho, S.N., Northrop, J.P., and Crabtree, G.R. 1996. Rapid shuttling of NF-AT in discrimination of $\mathrm{Ca}^{2+}$ signals and immunosuppression. Nature 383: $837-840$.

Torgerson, T.R., Colosia, A.D., Donahue, J.P., Lin, Y.Z., and Hawiger, J. 1998. Regulation of NF- $\mathrm{BB}, \mathrm{AP}-1, \mathrm{NFAT}$, and STAT1 nuclear import in $\mathrm{T}$ lymphocytes by noninvasive delivery of peptide carrying the nuclear localization sequence of NF-к B p50. J. Immunol. 161: 6084-6092.

Tsytsykova, A.V. and Goldfeld, A.E. 2000. Nuclear factor of activated $\mathrm{T}$ cells transcription factor NFATp controls superantigen-induced lethal shock. I. Exp. Med. 192: 581586.

Wada, H., Hasegawa, K., Morimoto, T., Kakita, T., Yanazume, 
Hogan et al.

T., Abe, M., and Sasayama, S. 2002. Calcineurin-GATA-6 pathway is involved in smooth muscle-specific transcription. J. Cell Biol. 156: 983-991.

Wang, D.Z., McCaffrey, P.G., and Rao, A. 1995. The cyclosporin-sensitive transcription factor NFATp is expressed in several classes of cells in the immune system. Ann. NY Acad. Sci. 766: 182-194.

Wen, H.Y., Xia, Y., Young, M.E., Taegtmeyer, H., and Kellems, R.E. 2002. The adenylosuccinate synthetase-1 gene is activated in the hypertrophied heart. J. Cell. Mol. Med. 6: 235243.

Windisch, A., Gundersen, K., Szabolcs, M.J., Gruber, H., and Lømo, T. 1998. Fast to slow transformation of denervated and electrically stimulated rat muscle. J. Physiol. 510: 623632.

Wu, H., Naya, F.J., McKinsey, T.A., Mercer, B., Shelton, J.M., Chin, E.R., Simard, A.R., Michel, R.N., Bassel-Duby, R., Olson, E.N., et al. 2000. MEF2 responds to multiple calciumregulated signals in the control of skeletal muscle fiber type. EMBO J. 19: 1963-1973.

Wu, H., Rothermel, B., Kanatous, S., Rosenberg, P., Naya, F.J., Shelton, J.M., Hutcheson, K.A., DiMaio, J.M., Olson, E.N., Bassel-Duby, R., et al. 2001. Activation of MEF2 by muscle activity is mediated through a calcineurin-dependent pathway. $E M B O$ J. 20: 6414-6423.

Xia, Y., McMillin, J.B., Lewis, A., Moore, M., Zhu, W.G., Williams, R.S., and Kellems, R.E. 2000. Electrical stimulation of neonatal cardiac myocytes activates the NFAT3 and GATA4 pathways and up-regulates the adenylosuccinate synthetase 1 gene. J. Biol. Chem. 275: 1855-1863.

Yang, J., Rothermel, B., Vega, R.B., Frey, N., McKinsey, T.A., Olson, E.N., Bassel-Duby, R., and Williams, R.S. 2000. Independent signals control expression of the calcineurin inhibitory proteins MCIP1 and MCIP2 in striated muscles. Circ. Res. 87: E61-E68.

Yang, T.T., Xiong, Q., Enslen, H., Davis, R.J., and Chow, C.W. 2002. Phosphorylation of NFATc4 by p38 mitogen-activated protein kinases. Mol. Cell. Biol. 22: 3892-3904.

Yang, X.Y., Wang, L.H., Chen, T., Hodge, D.R., Resau, J.H., DaSilva, L., and Farrar, W.L. 2000. Activation of human T lymphocytes is inhibited by peroxisome proliferator-activated receptor $\gamma(\operatorname{PPAR} \gamma)$ agonists. PPAR $\gamma$ co-association with transcription factor NFAT. J. Biol. Chem. 275: 45414544.

Yasuda, H., Shima, N., Nakagawa, N., Yamaguchi, K., Kinosaki, M., Mochizuki, S., Tomoyasu, A., Yano, K., Goto, M., Murakami, A., et al. 1998. Osteoclast differentiation factor is a ligand for osteoprotegerin/osteoclastogenesis-inhibitory factor and is identical to TRANCE/RANKL. Proc. Natl. Acad. Sci. 95: 3597-3602.

Yui, M.A., Hernandez-Hoyos, G., and Rothenberg, E.V. 2001. A new regulatory region of the IL-2 locus that confers positionindependent transgene expression. J. Immunol. 166: 17301739.

Zaccolo, M., Magalhaes, P., and Pozzan, T. 2002. Compartmentalisation of cAMP and $\mathrm{Ca}^{2+}$ signals. Curr. Opin. Cell Biol. 14: $160-166$.

Zhou, B., Cron, R.Q., Wu, B., Genin, A., Wang, Z., Liu, S., Robson, P., and Baldwin, H.S. 2002. Regulation of the murine Nfatc1 gene by NFATc2. J. Biol. Chem. 277: 10704-10711.

Zhu, J., Shibasaki, F., Price, R., Guillemot, J.C., Yano, T., Dötsch, V., Wagner, G., Ferrara, P., and McKeon, F. 1998. Intramolecular masking of nuclear import signal on NF-AT4 by casein kinase I and MEKK1. Cell 93: 851-861. 


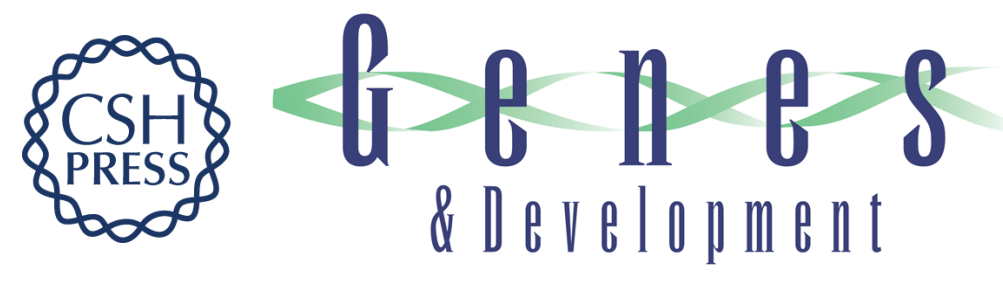

\section{Transcriptional regulation by calcium, calcineurin, and NFAT}

Patrick G. Hogan, Lin Chen, Julie Nardone, et al.

Genes Dev. 2003, 17:

Access the most recent version at doi:10.1101/gad.1102703

References This article cites 216 articles, 108 of which can be accessed free at: http://genesdev.cshlp.org/content/17/18/2205.full.html\#ref-list-1

License

Email Alerting Receive free email alerts when new articles cite this article - sign up in the box at the top Service right corner of the article or click here.

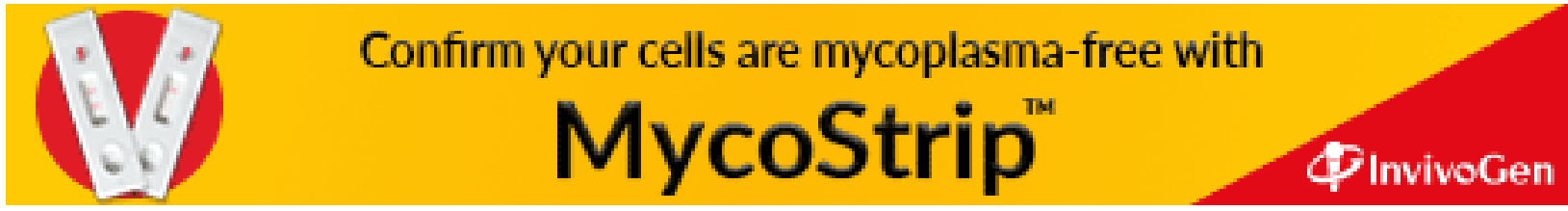

